\title{
Using the chemical equilibrium partitioning space to explore factors influencing the phase distribution of compounds involved in secondary organic aerosol formation
}

\author{
F. Wania ${ }^{1,2}$, Y. D. Lei ${ }^{1,2,3}$, C. Wang ${ }^{1,2}$, J. P. D. Abbatt ${ }^{2}$, and K.-U. Goss ${ }^{4,5}$ \\ ${ }^{1}$ Department of Physical and Environmental Sciences, University of Toronto Scarborough, 1265 Military Trail, Toronto, \\ Ontario, M1C 1A4, Canada \\ ${ }^{2}$ Department of Chemistry, University of Toronto, Toronto, Ontario, M1C 1A4, Canada \\ ${ }^{3}$ Department of Chemical Engineering and Applied Chemistry, University of Toronto, Toronto, Ontario, M1C 1A4, Canada \\ ${ }^{4}$ Department of Analytical Environmental Chemistry, Centre for Environmental Research UFZ Leipzig-Halle, \\ Permoserstraße 15, 04318 Leipzig, Germany \\ ${ }^{5}$ Institute of Chemistry, University of Halle-Wittenberg, Kurt-Mothes-Straße 2, 06120 Halle, Germany \\ Correspondence to: F. Wania (frank.wania@utoronto.ca)
}

Received: 22 September 2014 - Published in Atmos. Chem. Phys. Discuss.: 23 October 2014

Revised: 16 January 2015 - Accepted: 2 March 2015 - Published: 27 March 2015

\begin{abstract}
Many atmospheric and chemical variables influence the partitioning equilibrium between gas phase and condensed phases of compounds implicated in the formation of secondary organic aerosol (SOA). The large number of factors and their interaction makes it often difficult to assess their relative importance and concerted impact. Here we introduce a two-dimensional space which maps regions of dominant atmospheric phase distribution within a coordinate system defined by equilibrium partition coefficients between the gas phase, an aqueous phase and a water-insoluble organic matter (WIOM) phase. Placing compounds formed from the oxidation of $n$-alkanes, terpenes and mono-aromatic hydrocarbons on the maps based on their predicted partitioning properties allows for a simple graphical assessment of their equilibrium phase distribution behaviour. Specifically, it allows for the simultaneous visualisation and quantitative comparison of the impact on phase distribution of changes in atmospheric parameters (such as temperature, salinity, WIOM-phase polarity, organic aerosol load, and liquid water content) and chemical properties (such as oxidation state, molecular size, functionalisation, and dimerisation). The graphical analysis reveals that the addition of hydroxyl, carbonyl and carboxyl groups increases the affinity of aliphatic, alicyclic and aromatic hydrocarbons for the aqueous phase more rapidly than their affinity for WIOM, sug-
\end{abstract}

gesting that the aqueous phase may often be relevant even for substances that are considerably larger than the $\mathrm{C} 2$ and C3 compounds that are typically believed to be associated with aqueous SOA. In particular, the maps identify some compounds that contribute to SOA formation if partitioning to both WIOM and aqueous phase is considered but would remain in the gas phase if either condensed phase were neglected. For example, many semi-volatile $\alpha$-pinene oxidation products will contribute to aqueous SOA under the conditions of high liquid water content encountered in clouds but would remain vapours in wet aerosol. It is conceivable to develop parameterisations of "partitioning basis sets" that group compounds with comparable partitioning properties, which - when combined with data on the abundance of those groups of compounds - could serve in the simulation of SOA formation.

\section{Introduction}

The phase distribution of oxidised organic compounds between the gas phase and the condensed phases present in the atmosphere, and how that distribution is affected by atmospheric and chemical variables, is central to the understanding and quantification of the formation of secondary or- 
ganic aerosol (SOA) (Hallquist et al., 2009). For example, the molecular size of the compounds and the functional groups they contain have a strong influence on their preference for either the gas phase or the condensed phase(s) making up an aerosol particle. Atmospheric temperature strongly impacts that phase equilibrium. The concentration and the polarity of the organic particulate matter present in the atmosphere play a role, as do relative humidity and the resultant liquid water content of the atmosphere. The presence of electrolytes such as ammonium sulfate and sodium chloride further modifies the gas phase-aqueous phase equilibrium. How all these variables impact gas-particle partitioning is reasonably well understood and in most cases can even be quantified with some confidence (e.g. Zuend and Seinfeld, 2012; Shiraiwa et al., 2013). Nevertheless, due to the large number of the variables and their interaction, it is often difficult to assess the relative importance of each of these variables and to fully comprehend the concerted impact of all of them acting together. In fact, different variables will be important for different chemicals and under different atmospheric circumstances.

Graphical methods illustrating the effect of multiple variables within a common framework can be a powerful tool for understanding their relative importance and concerted impact (e.g. Wong and Wania, 2011). They can also aid in the identification and prioritisation of data gaps by indicating for which compounds and which circumstances a more precise quantification of the effect of a variable on phase partitioning is required and when approximate knowledge can be tolerated.

Ten years ago, we introduced the chemical partitioning space as a graphical method for furthering the understanding of the concerted impact of multiple variables on the phase distribution of semi-volatile organic trace contaminants, such as polycyclic aromatic hydrocarbons and polychlorinated biphenyls, in the atmosphere (Lei and Wania, 2004). The basic idea of the chemical partitioning space is to calculate and display regions of dominant phase distribution within a coordinate system defined by equilibrium phase partition coefficients, and then to place substances on the resulting maps based on their partitioning properties under certain prevailing conditions (e.g. of temperature). This allows for a simple graphical assessment of the substances' equilibrium phase distribution behaviour and, in turn, their depositional and reactive fate (Lei and Wania, 2004; Westgate and Wania, 2013). We believe, and seek to demonstrate here, that the chemical partitioning space could also be used to gain a deeper appreciation of the impact of various chemical and atmospheric variables on the phase distribution behaviour of SOA compounds. Because SOA formation strongly depends on the phase distribution behaviour of those substances, this also amounts to an exploration of the impact of those variables on the likelihood and the extent of SOA formation, as well as on the nature of the SOA formed.

The atmospheric chemistry community has a long tradition of using graphical tools to illustrate and advance understanding of atmospheric processes (e.g. Pankow and Barsanti, 2009; Heald et al., 2010; Kroll et al., 2011; Isaacman et al., 2011; Donahue et al., 2011, 2012; Cappa and Wilson, 2012), and there are precedents of displaying the phase distribution behaviour of SOA compounds as a function of chemical equilibrium partitioning parameters. The volatility basis set (VBS) approach by Donahue et al. (2006, 2011, 2012), in both its one-dimensional and two-dimensional manifestations, is sometimes used to indicate the distribution between gas and particle phase as a function of organic aerosol load and a compound's saturation concentration, which is defined as the reciprocal of a gas-particle partition coefficient and typically derived from saturation vapour pressure (Donahue et al., 2006). Similarly, Volkamer et al. (2009) displayed the distribution of glyoxal between gas and aqueous phase as a function of an effective Henry's law constant and the atmospheric liquid water content. However, to the best of our knowledge, no attempt has been made so far to similarly display graphically the distribution behaviour of SOA compounds between the gas phase, the atmospheric liquid water phase and the organic aerosol phase at the same time. Notably, the two-dimensional representations of organic compounds used in the SOA community employ a chemical equilibrium partitioning parameter for at most one of the two dimensions and thus do not have a sole focus on phase distribution. Even if they do consider phase distribution behaviour (e.g. the 2-D VBS; Donahue et al., 2011, 2012), the existence of a liquid water phase in the atmosphere is ignored. Recently, Hodzic et al. (2014) placed SOA compounds in a two-dimensional space defined by saturation concentration and effective Henry's law constant in order to observe and derive relationships between these two parameters for different groups of SOA compounds.

After first introducing the chemical partitioning space for the atmosphere, we explain how to place SOA compounds within the space and how to account for the influence of various variables on that placement. Using the partitioning space we then illustrate the impact of prediction uncertainty, temperature, salting-out effect, phase polarity, liquid water content, organic aerosol load and chemical ageing (i.e. functionalisation and oligomerisation) on the phase distribution of selected oxidation products of $n$-alkanes, biogenic terpenes and aromatic hydrocarbons.

\section{Methods}

\subsection{Defining the chemical partitioning space}

The equilibrium partition coefficient of a chemical between two phases $\mathrm{X}$ and $\mathrm{Y}$ is defined as

$K_{\mathrm{X} / \mathrm{Y}}=\frac{C_{\mathrm{X}}}{C_{\mathrm{Y}}}$,

where $C_{\mathrm{X}}$ and $C_{\mathrm{Y}}$ are the concentrations in phase $\mathrm{X}$ and $\mathrm{Y}$ in units of mol m${ }^{-3}$ of phase. $K_{\mathrm{X} / \mathrm{Y}}$ thus has units of $\mathrm{m}^{3}$ of 
phase $\mathrm{Y}$ per $\mathrm{m}^{3}$ of phase $\mathrm{X}$. In a system consisting of the gas $(\mathrm{G})$ phase, an aqueous (W) phase and a water-insoluble organic matter (WIOM) phase, there are three partition coefficients, which are related to each other according to

$K_{\mathrm{W} / \mathrm{G}}=\frac{K_{\mathrm{W} / \mathrm{WIOM}}}{K_{\mathrm{G} / \mathrm{WIOM}}}$.

Two of the three coefficients are therefore sufficient to describe a chemical's relative preferences for the three phases. Two coefficients in logarithmic form can be used to define a two-dimensional coordinate system, which we call the chemical partitioning space. In Fig. $1 \mathrm{a}, \log K_{\mathrm{W} / \mathrm{G}}$ and $\log$ $K_{\mathrm{WIOM} / \mathrm{G}}$ are used to define such a space.

The equilibrium partition coefficient between WIOM and the gas phase $\left(K_{\mathrm{WIOM} / \mathrm{G}}\right)$ on the $x$ axis is related to the gasparticle partition coefficient $K$ ' in units of $\mathrm{m}^{3} \mu \mathrm{g}^{-1}$ (Pankow, 2003) through

$K_{\mathrm{WIOM} / \mathrm{G}}=K^{\prime} \delta_{\mathrm{WIOM}} \frac{10^{6} \mu \mathrm{g}}{\mathrm{g}}$,

where $\delta_{\text {WIOM }}$ is the density of WIOM in units of $\mathrm{g} \mathrm{m}^{-3}$. The equilibrium partition coefficient between water and gas phase $K_{\mathrm{W} / \mathrm{G}}$ on the $y$ axis is related to the Henry's law constants $H$ in units of $\mathrm{mol} \mathrm{Pa}^{-1} \mathrm{~m}^{-3}$, or to $H^{\prime}$ in the non-SI units of $\mathrm{M} \mathrm{atm}^{-1}$ favoured by the atmospheric chemistry community, through

$K_{\mathrm{W} / \mathrm{G}}=H R T=H^{\prime} R T \times \frac{1 \mathrm{atmL}}{101.325 \mathrm{~Pa} \mathrm{~m}^{3}}$.

where $R$ is the ideal gas constant $\left(8.314 \mathrm{~Pa} \mathrm{~m}^{3} \mathrm{~K}^{-1} \mathrm{~mol}^{-1}\right)$ and $T$ is absolute temperature in $\mathrm{K}$. A chemical can be placed in such a coordinate system based on its equilibrium partition coefficients.

We should mention that the use of the term WIOM does not imply that the compounds making up this phase necessarily have low water solubility. Even relatively water-soluble compounds can have a higher preference for solvation in an organic phase than in a mostly aqueous phase.

\subsection{Displaying chemical phase distribution in the partitioning space}

If a three-phase system consisting of gas, water and WIOM is at chemical equilibrium, the fraction $\Phi_{X}$ of the total amount of a chemical that is in one of the three phases can be calculated using (Lei and Wania, 2004)

$$
\begin{aligned}
& \phi_{\mathrm{G}}=1 /\left(1+K_{\mathrm{W} / \mathrm{G}} \frac{V_{\mathrm{W}}}{V_{\mathrm{G}}}+K_{\mathrm{WIOM} / \mathrm{G}} \frac{V_{\mathrm{WIOM}}}{V_{\mathrm{G}}}\right), \\
& \phi_{\mathrm{W}}=1 /\left(1+K_{\mathrm{G} / \mathrm{W}} \frac{V_{\mathrm{G}}}{V_{\mathrm{W}}}+K_{\mathrm{WIOM} / \mathrm{W}} \frac{V_{\mathrm{WIOM}}}{V_{\mathrm{W}}}\right), \\
& \phi_{\mathrm{WIOM}}=1 /\left(1+K_{\mathrm{G} / \mathrm{WIOM}} \frac{V_{\mathrm{G}}}{V_{\mathrm{WIOM}}}+K_{\mathrm{W} / \text { WIOM }} \frac{V_{\mathrm{W}}}{V_{\mathrm{WIOM}}}\right) .
\end{aligned}
$$

This means that the chemical's phase distribution depends only on its equilibrium partition coefficients and the phase volumes $V_{\mathrm{X}}$ in $\mathrm{m}^{3}$. In the atmosphere, $V_{\mathrm{W}}$ and $V_{\mathrm{WIOM}}$ are negligibly small compared to $V_{\mathrm{G}}$ and the volume ratios $V_{\mathrm{W}} / V_{\mathrm{G}}$, and $V_{\mathrm{WIOM}} / V_{\mathrm{G}}$ can be calculated from the liquid water content (LWC) and the organic aerosol load (OAL) in units of $\mu \mathrm{g} \mathrm{m}^{-3}$ using

$$
\begin{aligned}
& \frac{V_{\mathrm{W}}}{V_{\mathrm{G}}}=\mathrm{LWC} \text { in } \mu \mathrm{g} \mathrm{m}^{-3} \times 10^{-6} \frac{\mathrm{g}}{\mu \mathrm{g}} \times 10^{-6} \frac{\mathrm{m}^{3}}{\mathrm{~g}}, \\
& \frac{V_{\mathrm{WIOM}}}{V_{\mathrm{G}}}=\text { OAL in } \mu \mathrm{g} \mathrm{m}^{-3} \times 10^{-6} \frac{\mathrm{g}}{\mu \mathrm{g}} \times 10^{-6} \frac{\mathrm{m}^{3}}{\mathrm{~g}} .
\end{aligned}
$$

We thereby assume that water and WIOM have a density of $10^{6} \mathrm{~g} \mathrm{~m}^{-3}$.

If we now assume LWC and OAL to be fixed, the phase distribution as calculated in Eqs. (5)-(7) only depends on the partition coefficients and we can display the values of $\Phi_{\mathrm{G}}$, $\Phi_{\mathrm{W}}$, and $\Phi_{\mathrm{WIOM}}$ within the partitioning space. In Fig. 1a this has been done assuming a LWC of $10 \mu \mathrm{g} \mathrm{m}^{-3}$ and an OAL of $10 \mu \mathrm{g} \mathrm{m}^{-3}$. In the red-coloured upper left of the partitioning space are chemicals with low $K_{\mathrm{W} / \mathrm{G}}$ and low $K_{\mathrm{WIOM} / \mathrm{G}}$, i.e. chemicals favouring the gas phase over the aqueous phase and WIOM. Accordingly they are predominantly in the gas phase (different shades of red are used to indicate areas of the space where $\Phi_{\mathrm{G}}$ exceeds 50, 90 and $99 \%$ ). In the bluecoloured lower left of the space are chemicals with high $K_{\mathrm{W} / \mathrm{G}}$ and low $K_{\mathrm{WIOM} / \mathrm{G}}$, i.e. highly water-soluble chemicals that favour the gas phase over the WIOM phase and thus partition predominantly into the aqueous phase (different shades of blue indicate areas of the space where $\Phi_{\mathrm{W}}$ exceeds 50,90 and $99 \%$ ). Finally, in the green-coloured upper right of the space are chemicals with low $K_{\mathrm{W} / \mathrm{G}}$ and high $K_{\mathrm{WIOM} / \mathrm{G}}$, i.e. sparingly water-soluble substances of low volatility that partition predominantly into the WIOM phase (different shades of green indicate areas of the space where $\Phi_{\text {WIOM }}$ exceeds 50,90 and $99 \%$ ).

The lines between the fields coloured in red, blue and green $\left(\Phi_{\mathrm{G}}=\Phi_{\mathrm{W}}=\Phi_{\mathrm{WIOM}}=50 \%\right)$ indicate the $K_{\mathrm{W} / \mathrm{G}}$ and $K_{\text {WIOM/G }}$ thresholds, where the transition of chemicals from mostly in the gas phase to mostly in the aqueous or WIOM phase occurs (Fig. 1a). The vertical threshold between predominant partitioning into gas and WIOM phase occurs at $\log K_{\mathrm{WIOM} / \mathrm{G}}=\log \left(V_{\mathrm{G}} / V_{\mathrm{WIOM}}\right)$ and the horizontal threshold between predominant partitioning into gas and aqueous phase at $\log K_{\mathrm{W} / \mathrm{G}}=\log \left(V_{\mathrm{G}} / V_{\mathrm{W}}\right)$. At the assumed LWC and OAL of $10 \mu \mathrm{g} \mathrm{m}^{-3}$, this corresponds to $\log K_{\mathrm{W} / \mathrm{G}}$ and $\log$ $K_{\text {WIOM/G }}$ values of 11 .

Because of the thermodynamic relationship of Eq. (2), $K_{\text {WIOM/W }}$ equals $K_{\text {WIOM/G }}$ divided by $K_{\text {W/G }}$, and diagonal lines from the upper left to the lower right in the partitioning space designate lines of equal $K_{\mathrm{WIOM} / \mathrm{w}}$. The diagonal lines in the lower right of Fig. 1a therefore show where the transition from dominant partitioning into WIOM and aqueous phase takes place. If liquid water and WIOM are equally abundant (LWC and OAL is $10 \mu \mathrm{g} \mathrm{m}^{-3}$ ) the threshold falls at $\log K_{\mathrm{WIOM} / \mathrm{G}}=\log \left(V_{\mathrm{G}} / V_{\mathrm{WIOM}}\right)=\log 1=0$. 

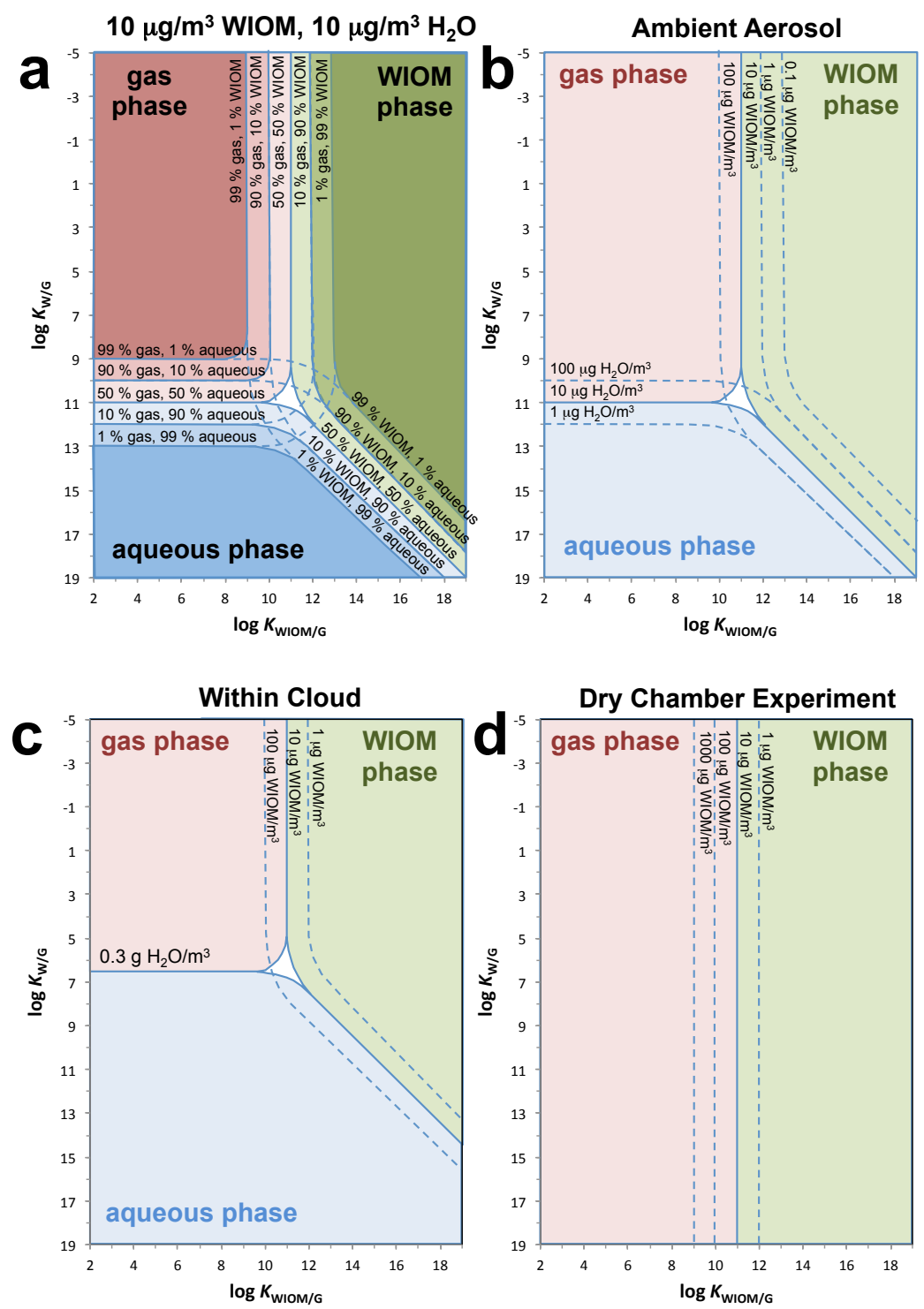

Figure 1. Different versions of the chemical partitioning space for the atmosphere, showing in red, blue and green the combinations of partitioning properties that lead to dominant equilibrium partitioning to the gas, aqueous and water-insoluble organic matter (WIOM) phase, respectively. Panel (a) refers to typical atmospheric conditions of $10 \mu \mathrm{g}$ of both WIOM and liquid water per $\mathrm{m}^{3}$ of air and demonstrates that the transition from 1 (10) to 99 (90)\% in a particular phase occurs over a 4 (2) order of magnitude range in a partition coefficient. A clear atmosphere (a and b), a cloud (c) and a dry chamber experiment (d) only differ in terms of the relative volume of the three phases present, leading to shifts in the thresholds indicating $50 \%$ partitioning into any one phase. Dashed lines in (b)-(d) indicate the $50 \%$ threshold for various loadings of WIOM and various liquid water contents.

This threshold could obviously also be calculated from the other two thresholds $\left(\log K_{\mathrm{WIOM} / \mathrm{G}}-\log K_{\mathrm{W} / \mathrm{G}}=11-\right.$ $\left.11=0=\log K_{\mathrm{WIOM} / \mathrm{G}}\right)$. The white triangle in the centre of the three coloured areas designates the partitioning properties of chemicals that partition to none of the three phases to more than $50 \%$, i.e. they are present in equal proportions in all three phases. Finally, the two triangular areas with bowshaped flanks, surrounding the white triangle and delineated by dashed lines, encompass properties of chemicals that par- tition mostly in one phase, with the remainder split between the other two phases.

Of course, the thresholds are not fixed, but depend on the size of the aqueous and WIOM phase in the atmosphere. OAL in the atmosphere ranges between 0.1 and $100 \mu \mathrm{g} \mathrm{m}^{-3}$, with most measurements yielding OAL between 1 and $10 \mu \mathrm{g} \mathrm{m}^{-3}$ (Jimenez et al., 2009). In Fig. 1b, broken vertical lines indicate where the threshold between predominant partitioning into gas and WIOM phase would fall if OALs of $0.1,1$, and $100 \mu \mathrm{g} \mathrm{m}^{-3}$ prevailed. With each order- 
of-magnitude increase in the OAL, the threshold moves one $\log$ unit to the left, i.e. more volatile chemicals (i.e. with lower $\log K_{\mathrm{WIOM} / \mathrm{G}}$ ) will shift their equilibrium phase distribution from the gas to the WIOM phase. Similarly, the broken horizontal lines in Fig. 1b indicate the threshold between predominant partitioning into gas and aqueous phase if larger or lower volumes of water were associated with the aerosol, i.e. at LWCs of 100 or $1 \mu \mathrm{g} \mathrm{m}^{-3}$, respectively. With each order of magnitude increase in the LWC, the threshold moves one $\log$ unit up, i.e. more volatile chemicals (i.e. with lower $\log K_{\mathrm{W} / \mathrm{G}}$ ) will shift their phase distribution from the gas to the aqueous phase.

The amount of liquid water in an aerosol depends on temperature, relative humidity, and particle concentration and type, i.e. its hygroscopicity. A range of LWC between 1 and $100 \mu \mathrm{g} \mathrm{m}^{-3}$ was deemed plausible based on calculations with the E-AIM model (Wexler and Clegg, 2002). At high relative humidity, and if the aerosol particles can act as cloud condensation nuclei, water starts to condense to a much greater extent and the LWC will adopt values that are more than 5 orders of magnitude higher. Figure 1c thus maps $\Phi_{\mathrm{G}}, \Phi_{\mathrm{W}}$ and $\Phi_{\mathrm{WIOM}}$ for a LWC of $0.3 \mathrm{~g} \mathrm{~m}^{-3}\left(V_{\mathrm{W}} / V_{\mathrm{G}}=\right.$ $3 \times 10^{-7} \mathrm{~m}^{3} \mathrm{~m}^{-3}$ ), which is typical for conditions within a cloud. The horizontal threshold moves sharply up to a $\log$ $K_{\mathrm{W} / \mathrm{G}}$ of 6.5 , which means that, at equilibrium, many more chemicals will partition into the aqueous phase of a cloud than in an aerosol under clear-sky conditions (Fig. 1b). We note that the left side of the partitioning space plots is similar to a figure illustrating the partitioning of water-soluble molecules to cloud, fog and aerosol liquid water presented previously (Fig. 8 in Volkamer et al., 2009).

In atmospheric chamber experiments conducted at low relative humidity, the liquid water content of aerosol may be negligibly low. In that case the fraction in the aqueous phase $\Phi_{\mathrm{W}}$ is also negligible, and the blue field disappears from the partitioning space altogether (Fig. 1d), or rather the vertical threshold moves so far down that it no longer falls within the range of displayed $K_{\mathrm{W} / \mathrm{G}}$ values. During some chamber experiments, OAL exceed levels observed in ambient air (e.g. $1000 \mu \mathrm{g} \mathrm{m}^{-3}$ ) and the vertical threshold can move far to the left, i.e. to a $\log K_{\mathrm{WIOM} / \mathrm{G}}$ of around 9 (Fig. 1d).

We should stress that while Fig. 1b to d only show the threshold for shifts in dominant phase partitioning, i.e. the lines where $50 \%$ of a chemical is in one phase, even very small fractions of a chemical partitioning into a phase could be important, for example, if they have an efficient reactive or depositional sink within that phase or if they have reached high concentrations in their preferred phases.

\subsection{Major assumptions underlying the chemical partitioning space approach}

Before proceeding to consider and interpret chemical partitioning space plots for SOA compounds, it is worthwhile discussing two major assumptions that are made when draw- ing these diagrams. The first assumption is that chemicals achieve quasi-instantaneous equilibrium between the phases present in the atmosphere. The second is that the condensed phase separates into a largely aqueous phase and a phase largely made up of water-insoluble organic matter. In particular, we do not consider the possibility of the simultaneous presence of two immiscible, largely non-aqueous organic phases, e.g. a non-polar hydrocarbon-like phase separated from a polar, highly oxidised, non-aqueous phase. (Such a phase separation is, for example, predicted by the 2-D VBS approach (Donahue et al., 2012), but this approach also disregards the presence of water in the condensed phase.) Because of the equilibrium assumption, particle morphology, i.e. the spatial arrangement of the two condensed phases relative to each other, is of no concern in our analysis (Shiraiwa et al., 2013).

While the timescale of chemical diffusion in largely liquid-like atmospheric aerosol phases was long judged sufficiently short to assume that equilibrium partitioning prevails most of the time, more recently evidence has begun to emerge that suggests that the physical state of organic aerosol may at times be semi-solid or glassy (Mikhailov et al., 2009; Virtanen et al., 2010) and that the rate of mass transfer in such phases is too slow to assure equilibrium distribution at atmospheric timescales (e.g. Koop et al., 2011; Perraud et al., 2012). However, this view is not yet universally acknowledged and there is, similarly, experimental evidence of the validity of the quasi-instantaneous equilibrium assumption (e.g. Saleh et al., 2013). In any case, even if chemical equilibrium is not always achieved, the equilibrium distribution is still of paramount importance as the state that the system strives to reach.

Support for separation into predominantly organic and aqueous phases in aerosol stems from laboratory (e.g. Song et al., 2012), field (You et al., 2012) and theoretical investigations (e.g. Bertram et al., 2011; Zuend and Seinfeld, 2012). These same investigations also suggest the possibility of the formation of a single condensed phase at high relative humidity and if the organic material is highly oxidised. Incidentally, even though we assume the presence of a WIOM phase separate from an aqueous phase when drawing the partitioning space map, the map can still indicate when such phase separation is unlikely. That is, if most of the organic compounds present in an aerosol fall in the part of the partitioning space indicating predominant partitioning into the aqueous phase and few fall into the part corresponding to partitioning into WIOM, it stands to reason that no WIOM phase will form and that instead all of the organic material present will be in a single condensed phase.

\subsection{Estimating the equilibrium partition coefficients for SOA compounds}

A chemical occupies a place within the chemical partitioning space based on its partition coefficients $K_{\mathrm{W} / \mathrm{G}}$ and 
$K_{\mathrm{WIOM} / \mathrm{G}}$. Ideally, one would use measured partition coefficients to locate a substance in the partitioning space (Lei and Wania, 2004). However, because such data are not available for many, if not most, of the substances involved in SOA formation, we need to rely on prediction methods when trying to locate SOA compounds in the chemical partitioning space. We recently applied three such methods to the prediction of $K_{\mathrm{WIOM} / \mathrm{G}}$ for substances involved in SOA formation (Wania et al., 2014). These methods, which were first applied to the issue of gasparticle partitioning by Arp et al. (2008) and Arp and Goss (2009), are poly-parameter linear free-energy relationships (ppLFERs) calibrated with empirical aerosol sorption data, the solvation models implemented in SPARC Performs Automated Reasoning in Chemistry (SPARC) (Hilal et al., 2004), and the quantum-chemical software COSMOtherm (version C30_1401 with BP_TZVP_C30_1401 parameterisation, COSMOlogic GmbH \& Co. KG, Leverkusen, Germany, 2014), which predict solvation equilibria from molecular structure alone. The same three methods can also be used to predict $K_{\mathrm{W} / \mathrm{G}}$.

We compiled the chemical identity of compounds believed to form during the oxidation of normal alkanes with 8 to 17 carbons (Jordan et al., 2008), terpenes (Chen and Griffin, 2005) and aromatic hydrocarbons (Forstner et al., 1997). Additional oxidation products of $\alpha$-pinene were taken from Camredon et al. (2010), Shilling et al. (2009) and Valorso et al. (2011). Molecular structures of a total of more than 350 molecules were drawn with ChemSketch (ACD/Labs, Advanced Chemistry Development Inc. Toronto, Canada), which yields each molecule's SMILES (simplified molecular-input line-entry system) string.

For the ppLFER approach, the molecules' solute descriptors were predicted with ABSOLV, which relies on a group contribution quantitative structure property relationship (ACD/Labs, Toronto, Canada). $K_{\mathrm{W} / \mathrm{G}}$ at different temperatures were calculated directly using the ppLFER equations given by Goss (2006). $K_{\text {WIOM/G }}$ at $15^{\circ} \mathrm{C}$ for four different aerosol particles (sampled from urban, suburban, rural and coastal sites during different seasons) were calculated using ppLFER equations by Arp et al. (2008), and adjusted for temperature using an enthalpy of phase partitioning estimated using the approach described in Wania et al. (2014). The temperature-adjusted $\log K_{\mathrm{WIOM} / \mathrm{G}}$ for the four aerosol samples was averaged.

SPARC directly predicts $K_{\mathrm{W} / \mathrm{G}}$ and $K_{\mathrm{WIOM} / \mathrm{G}}$ as a function of temperature when provided with a SMILES code. For the $K_{\text {WIOM/G }}$ prediction, SPARC requires a solvent to be specified, which should have solvation properties that resemble those of WIOM in SOA (Wania et al., 2014). As a default choice we used a relatively non-polar, hypothetical structure termed B, proposed to be an oligomerisation product of the oxidation of volatile aromatics (Kalberer et al., 2004; Arp and Goss, 2009; Wania et al., 2014). For the estimation of $K_{\mathrm{WIOM} / \mathrm{G}}$ of the oxidation products of $\alpha$ pinene, we additionally used two molecules as surrogate solvents that are themselves oxidation products of $\alpha$-pinene: a dimer formed by esterification of pinic acid and 10-hydroxypinonic acid, referred to as ESTER_dimer by Zuend and Seinfeld (2012), and 5-hydroperoxy-4-(hydroxymethyl)-5methyl-2-oxohexanoic acid, designated as $\mathrm{C} 813 \mathrm{OOH}$ in the Master Chemical Mechanism model. The latter chemical is highly oxygenated and polar.

Wania et al. (2014) describe the prediction of $K_{\mathrm{WIOM} / \mathrm{G}}$ for the $n$-alkane oxidation products using COSMOtherm and the surrogate solvent $\mathrm{B}$ mentioned above. COSMOtherm was similarly used to calculate $K_{\mathrm{W} / \mathrm{G}}$ for the $n$-alkane oxidation products. COSMOtherm was also applied to estimate $K_{\mathrm{W} / \mathrm{G}}$ and $K_{\mathrm{WIOM} / \mathrm{G}}$ at selected temperatures for $22 \alpha$-pinene oxidation products, using either structure B, ESTER_dimer and $\mathrm{C} 813 \mathrm{OOH}$ as surrogate solvents to represent WIOM.

The salting-out effect on aqueous phase-gas phase equilibrium was quantified by estimating a compound-specific Setschenow coefficient $K_{\mathrm{S}}$ in ammonium sulfate solution using a ppLFER by Wang et al. (2014) and then calculating a salt solution-gas phase equilibrium partition coefficient $K_{\mathrm{S} / \mathrm{G}}$ using

$\log K_{\mathrm{S} / \mathrm{G}}=\log K_{\mathrm{W} / \mathrm{G}}-$ [salt] $K_{\mathrm{S}}$,

where [salt] is the molar concentration of ammonium sulfate in aqueous salt solution, which was varied between 0 and $6.6 \mathrm{M}$, the latter corresponding to a supersaturated solution as may be encountered in aqueous aerosol (Zuend and Seinfeld, 2012).

All estimated partitioning data are given in an Excel $^{\circledR}$ file in the Supplement.

\section{Results}

\subsection{Placing the SOA compounds in the chemical partitioning space}

Figure 2 shows the location of the SOA compounds in the partitioning space. The chemicals are located based on their $K_{\text {W/G }}$ and $K_{\text {WIOM/G }}$ at $15^{\circ} \mathrm{C}$ estimated with SPARC using structure $\mathrm{B}$ as a surrogate for WIOM and assuming no salting-out effect. Differently coloured markers designate compounds derived from different precursors.

Comparing a chemical's location relative to the thresholds for dominant phase distribution, which were introduced in Fig. 1 and are integrated into Fig. 2, allows us to graphically deduce its phase distribution behaviour. It is apparent that the oxidation products of $n$-alkanes (blue dots in Fig. 2) generally have higher $\log K_{\mathrm{WIOM} / \mathrm{G}}$ and lower $K_{\mathrm{W} / \mathrm{G}}$ than the oxidation products of terpenes and aromatic hydrocarbons and therefore tend to have a higher affinity for the WIOM phase than the aqueous phase when they become insufficiently volatile to remain in the gas phase. Lower $K_{\mathrm{W} / \mathrm{G}}$ values of 


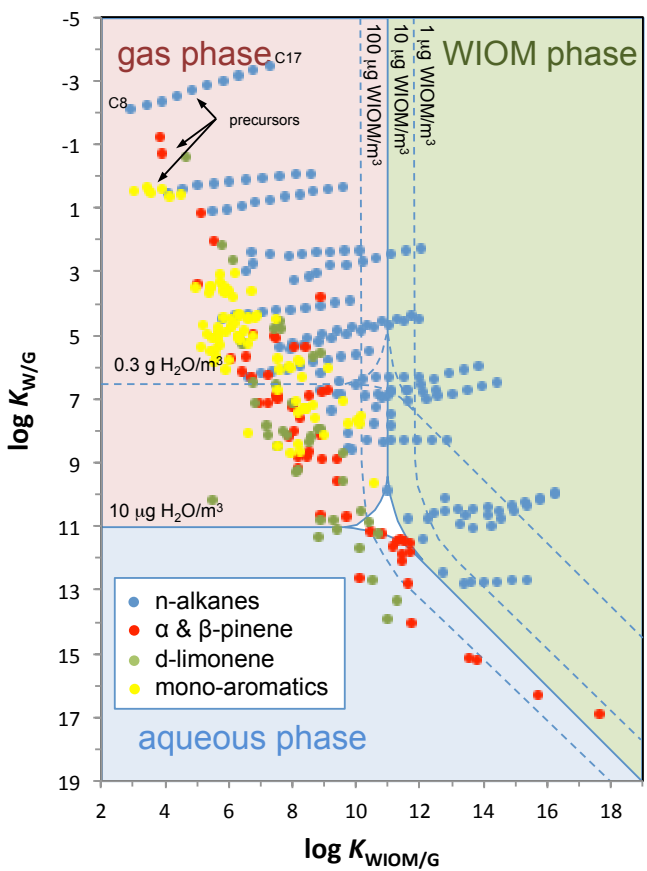

Figure 2. Placement of the selected oxidation products of $n$ alkanes, biogenic terpenes and mono-aromatic hydrocarbons in the partitioning space. $K_{\mathrm{WIOM} / \mathrm{G}}$ and $K_{\mathrm{W} / \mathrm{G}}$ at $15^{\circ} \mathrm{C}$ and $0 \mathrm{M}$ salt of the compounds were estimated using SPARC assuming the solvation properties of WIOM can be approximated by those of structure B.

the products formed from $\alpha$ - and $\beta$-pinene and d-limonene (green and red dots in Fig. 2, respectively) means that they cluster around the line separating predominant partitioning to WIOM and aqueous phase. The graphical analysis also suggests that most of the oxidation products of the monoaromatic hydrocarbons identified by Forstner et al. (1997) (yellow dots in Fig. 2) are too volatile to notably contribute to organic aerosol formation under most atmospheric conditions. SOA formed during the oxidation of mono-aromatics (Ng et al., 2007; Wyche et al., 2009) is therefore unlikely to be made up of the substances identified in Forstner et al. (1997) and displayed in Fig. 2. An exception is a cloud, where many oxidation products from all types of precursors could be expected to partition substantially into cloud water.

Figure 2 does not show the position of small water-soluble compounds, such as the $\mathrm{C} 2$ and $\mathrm{C} 3$ compounds typically associated with aqueous SOA (e.g. glyoxal, methylglyoxal, oxalic acid) (Lim et al., 2010). The distribution of these compounds between gas and particle phase is often strongly influenced by hydration and possibly other reactions in the aqueous phase (Ip et al., 2009; Volkamer et al., 2009; Kampf et al., 2013) leading to "effective" partition coefficients that are orders of magnitude higher than estimated ones (e.g. Rossignol et al., 2012). Furthermore, many smaller acids are expected to ionise substantially under the $\mathrm{pH}$ condition prevailing in aerosol water and the $K_{\mathrm{W} / \mathrm{G}}$ predicted for the neutral form may often underestimate the preference for the aqueous phase. Following Volkamer et al. (2009), it would be possible to locate these compounds in the partitioning space based on their "effective" partition coefficients, as long as these can be reliably derived.

Figure 3 is identical to Fig. 2, except that now the markers designating the SOA compound are coloured based on their average carbon oxidation state $\left(\mathrm{OS}_{\mathrm{C}}\right)$ and number of carbons $\left(n_{\mathrm{C}}\right)$. Figure $\mathrm{S} 1$ in the Supplement displays a similar plot based on the compounds' oxygen : carbon ratio $(\mathrm{O}: \mathrm{C})$. These plots allow us to relate a chemical's location in the partitioning space to its molecular size and oxidation state. An increase in $n_{\mathrm{C}}$ corresponds to a shift to the right in the chemical partitioning space, i.e. larger chemicals have a higher affinity for the WIOM phase relative to the gas phase. Increasing $n_{\mathrm{C}}$ in the form of methylene groups, on the other hand, hardly affects a chemical's relative affinity for water and the gas phase, i.e. an additional $-\mathrm{CH}_{2}-$ decreases vapour pressure and water solubility almost to the same extent. $n$ alkane oxidation products that only deviate in their chain length are arranged along lines that are parallel to the $x$ axis (Fig. 3a). If a series of compound varies in $n_{\mathrm{C}}$ because of additional aromatic carbons, such as the polycyclic aromatic hydrocarbons, the increase in $K_{\mathrm{WIOM} / \mathrm{G}}$ is accompanied by a smaller increase in $K_{\mathrm{W} / \mathrm{G}}$ (Lei and Wania, 2004). An increase in a compound's $\mathrm{OS}_{\mathrm{C}}$ is reflected by a shift down and slightly to the right in the partitioning space, i.e. more oxidised species have a higher relative affinity for the aqueous than the WIOM and gas phase. SOA compounds' $\mathrm{OS}_{\mathrm{C}}$ increases largely because of the addition of oxygen containing functional group, which leads to an increase in $K_{\mathrm{W} / \mathrm{G}}$. The $\mathrm{O}: \mathrm{C}$ ratio shows similar but less clear trends to the $\mathrm{OS}_{\mathrm{C}}$ (Fig. S1).

\subsection{Categorising compounds based on their atmospheric phase distribution behaviour}

We can now classify organic compounds based on their atmospheric phase distribution behaviour. Figure 4 assigns labels to different zones of the chemical partitioning space. Based on their tendency to partition to condensed phases, compounds are classified as volatile $(\mathrm{V})$, semi-volatile (SV), low volatile (LV) and extremely low volatile (ELV). Based on their preferred condensed phase, compounds are further categorised as hydrocarbon-like (HOC, preference for WIOM), oxygenated (OOC, no obvious preferred condensed phase) and water-soluble (WSOC, preference for aqueous phase).

At equilibrium, less than $1 \%$ of a volatile organic compound (VOC) $\left(\log K_{\mathrm{WIOM} / \mathrm{G}}\right.$ and $\left.\log K_{\mathrm{W} / \mathrm{G}}<8\right)$ is predicted to be in the condensed phase even under high-OAL conditions $\left(100 \mu \mathrm{g} \mathrm{m}^{-3}\right)$. A chemical is presumed to be a lowvolatility organic compound (LVOC) $\left(\log K_{\mathrm{WIOM} / \mathrm{G}}\right.$ and $\log$ $\left.K_{\mathrm{W} / \mathrm{G}}>14\right)$ if less than $1 \%$ is predicted to be in the gas phase even under low-OAL conditions $\left(1 \mu \mathrm{g} \mathrm{m}^{-3}\right)$. Semivolatile organic compounds $(\mathrm{SVOCs})\left(8<\log K_{\mathrm{WIOM} / \mathrm{G}}\right.$ or 

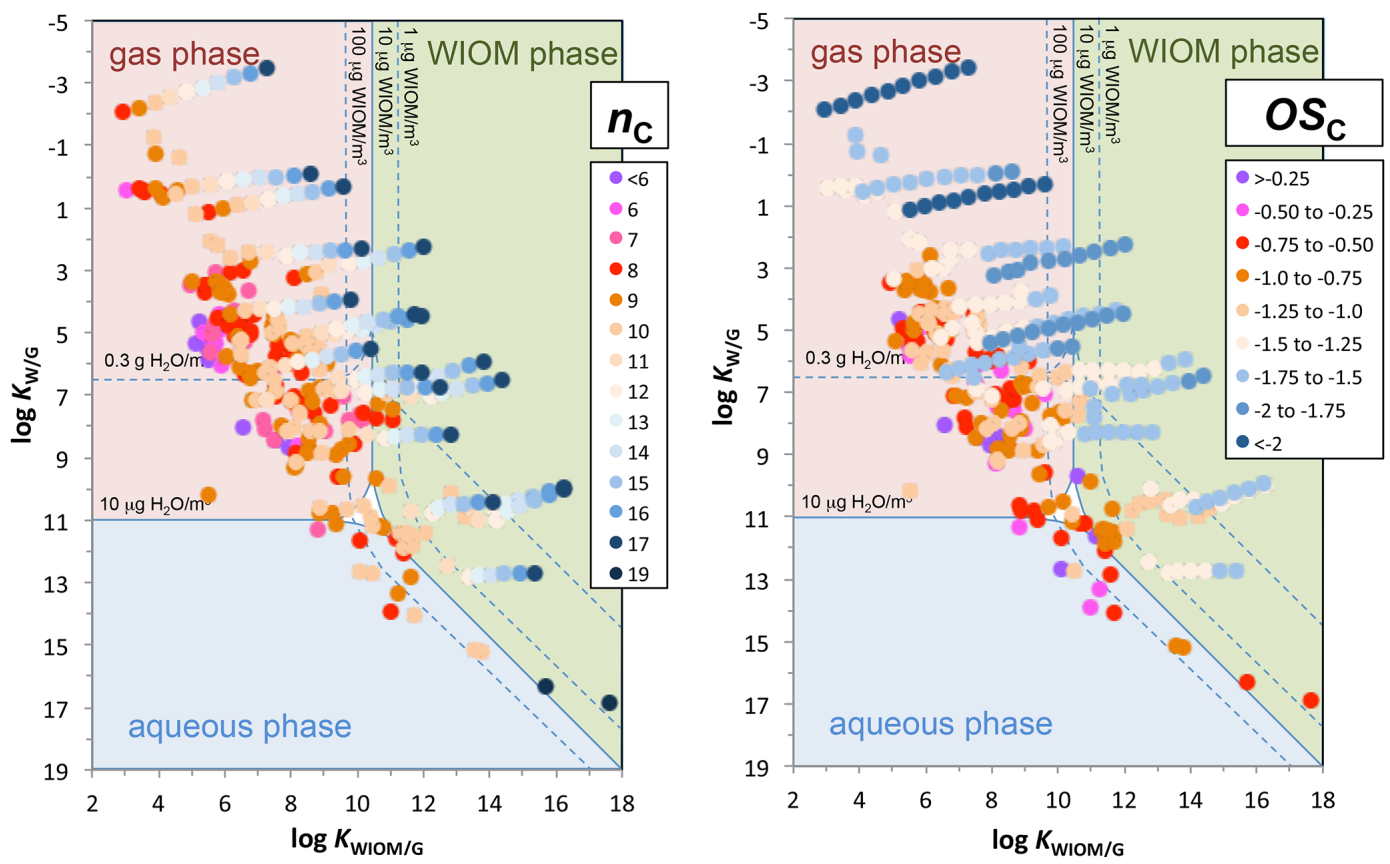

Figure 3. Same as Fig. 2, except that markers are coloured based on a chemical's number of carbon atoms $\left(n_{\mathrm{C}}\right)$ (left) or its average carbon oxidation state $\left(\mathrm{OS}_{\mathrm{C}}\right)$ (right).

$\left.\log K_{\mathrm{W} / \mathrm{G}}<14\right)$ are in between VOCs and LVOCs. Similarly, at equilibrium, less than $1 \%$ of an $\mathrm{HOC}\left(\log K_{\mathrm{WIOM} / \mathrm{W}}>3\right)$ partitions into the aqueous phase, even under low-OAL conditions, and less than $1 \%$ of a WSOC $\left(\log K_{\mathrm{WIOM} / \mathrm{W}}<-3\right)$ partitions into the WIOM phase, even if OAL is high. OOCs fall in between HOCs and WSOCs $\left(-3<\log K_{\mathrm{WIOM} / \mathrm{W}}<3\right)$. Because of the widely different LWC, SV-WSOCs occupy a different part of the partitioning space under clear conditions and in a cloud. Whereas chemicals with a $\log K_{\mathrm{W} / \mathrm{G}}<8$ are VOCs at low RH, that threshold shifts to a $\log K_{\mathrm{W} / \mathrm{G}}$ of 3.5 within a cloud.

The nomenclature in Fig. 4 builds upon previous classifications of SOA compounds (Kroll et al., 2011; Donahue et al., 2012). In particular, the aerosol mass spectrometry community uses HOA and OOA to refer to hydrocarbonlike and oxygenated organic aerosol. However, the use of the terms here may not always be entirely congruous with previous efforts. For example, our definition of SVOCs comprises some of the compounds that would be called intermediatevolatility organic compounds (IVOCs) and LVOCs by Donahue et al. (2012).

Figure 4 reveals that higher-generation oxidation products of monoterpenes and mono-aromatic hydrocarbons fall mostly into the SV-OOC category in the centre of the partitioning space, indicating that they may partition to a significant extent into gas, aqueous and WIOM phase depending on the prevailing atmospheric conditions. This also means that their exact placement in the space is important, because it will affect the predicted phase distribution. So far, we have used a single point to designate a chemical's location in the partitioning space, although this location is variable for two primary reasons: prediction uncertainty and environmental variability. In the next two sections, we will explore these sources of variability in more detail.

\subsection{Influence of prediction uncertainty on placement of $n$-alkane oxidation products in the partitioning space}

In order to evaluate the uncertainty of the placement of chemicals in the partitioning space, we sought to quantify the confidence of the $K_{\mathrm{WIOM} / \mathrm{G}}$ and $K_{\mathrm{W} / \mathrm{G}}$ predictions by comparing the results of different prediction methods. The values obtained for the partition coefficients of three $n$-alkanes (C9, $\mathrm{C} 13, \mathrm{C} 17)$ and their oxidation products at $25^{\circ} \mathrm{C}$ by ppLFER (average for four aerosols), SPARC (using structure B for WIOM) and COSMOtherm (using structure B for WIOM) are displayed in Fig. 5. The uncertainty of $K_{\mathrm{WIOM} / \mathrm{G}}$ had previously been explored in Wania et al. (2014) and had been found to be a composite of the uncertainty of the prediction method and the uncertainty of the conceptual approach (how well do a surrogate's solvation properties match those of the organic aerosol phase, and how representative are the solvation properties of the four real aerosol types characterised by Arp et al. (2008) of those of aerosol in general?). The uncertainty of the $K_{\mathrm{W} / \mathrm{G}}$ is solely due to the uncertainty of the prediction method.

We use arrows to illustrate the displacement of a chemical in the partitioning space when we apply different prediction 


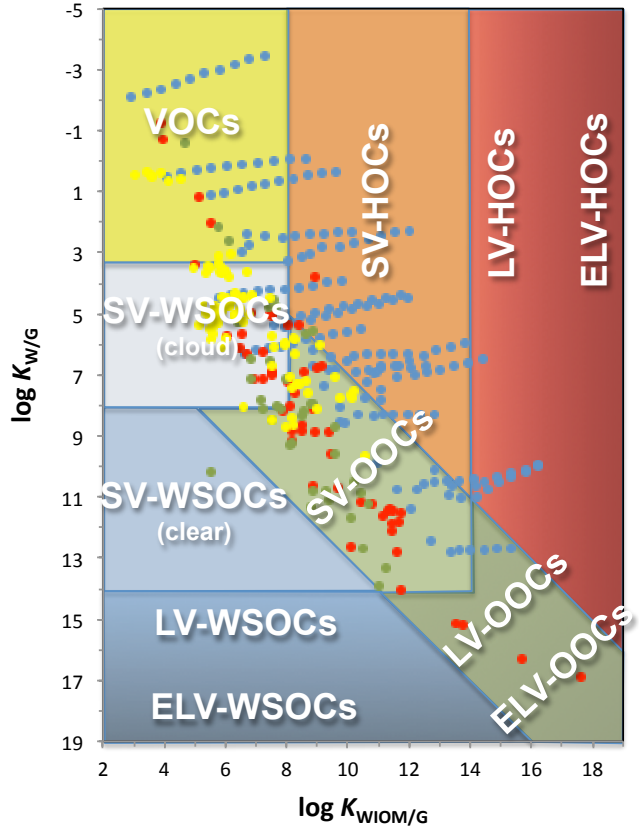

Figure 4. Same as Fig. 2, except that different regions of the chemical partitioning space have been named according to the type of compounds that fall into these regions.

methods: the origin of each arrow is the location obtained by SPARC predictions. The end of the blue and the red arrow is the location obtained using ppLFERs and COSMOtherm, respectively. The length of the arrow is thus a measure of the uncertainty of the prediction (the horizontal and vertical displacement indicating the discrepancy in $K_{\mathrm{WIOM} / \mathrm{G}}$ and $K_{\mathrm{W} / \mathrm{G}}$ predictions, respectively) and arrows consistently pointing in a particular direction indicate a bias of one method relative to another.

The arrows in Fig. 5 tend to get longer when moving from the upper left to the lower right of the partitioning space, suggesting that the discrepancy between predictions becomes larger as chemicals become less volatile. This is expected, as predictions for these less volatile, multi-functional chemicals involve an extrapolation from the type of chemicals for which empirical partitioning data are available and which are therefore the basis of the calibration of the ppLFER and also the SPARC method. The vertical displacements in Fig. 5 tend to be larger than the horizontal ones, indicating that the uncertainty of the $K_{\mathrm{W} / \mathrm{G}}$ prediction is higher than that of $K_{\mathrm{WIOM} / \mathrm{G}}$. Most arrows are pointing to the left, which means that SPARC predicts generally higher $K_{\text {WIOM/G }}$ than the other two methods. Most red arrows are pointing upwards, indicating that SPARC also predicts higher $K_{\mathrm{W} / \mathrm{G}}$ than COSMOtherm.

The uncertainty in the placement of chemicals falling into the area close to the phase transition between gas and WIOM phase is generally less than an order of magnitude for $K_{\mathrm{WIOM} / \mathrm{G}}$ and less than 2 orders of magnitude for $K_{\mathrm{W} / \mathrm{G}}$

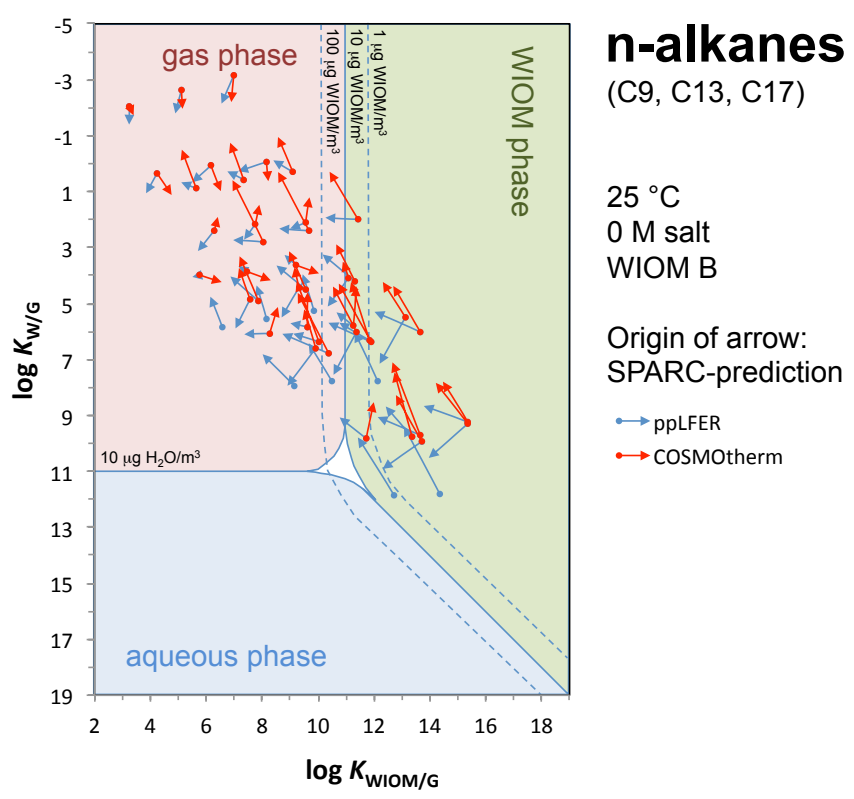

Figure 5. Arrows indicating the uncertainty of chemical placement in the partitioning space based on the discrepancy of $K_{\mathrm{WIOM} / \mathrm{G}}$ and $K_{\mathrm{W} / \mathrm{G}}$ predictions made with SPARC (origin of arrows), ppLFERs (tip of blue arrows) and COSMOtherm (tip of red arrows). For some compounds, no COSMOtherm predictions are available.

(Fig. 5). The latter is generally of little consequence because the oxidation products of the $n$-alkanes are not sufficiently polar to partition to the aqueous aerosol phase, unless the LWC is very high (i.e. in a cloud). The uncertainty of $K_{\mathrm{WIOM} / \mathrm{G}}$, on the other hand, is sufficiently large to significantly change the predicted partitioning behaviour of SVHOCs with a $\log K_{\mathrm{WIOM} / \mathrm{G}}$ ranging from 10 to 12 . It is, however, worth reiterating the observation of Wania et al. (2014) that the prediction uncertainty in $K_{\mathrm{WIOM} / \mathrm{G}}$ for the $n$-alkane oxidation products is much smaller than the prediction uncertainty of saturation vapour pressure normally used to predict the phase distribution behaviour of SOA compounds.

\subsection{Influence of environmental variability on placement of $\alpha$-pinene oxidation products in the partitioning space}

We use $\alpha$-pinene oxidation products to illustrate the effect of temperature, aqueous-phase salinity and WIOM-phase polarity on the placement of chemicals in the partitioning space. Because it is difficult to discuss the impact of environmental variability without also considering the prediction uncertainty discussed in Sect. 3.3, we produced multiple plots using different predictions. Figure $6 \mathrm{a}$ and $\mathrm{b}$ are based on SPARC- and COSMOtherm-predicted partition coefficients, respectively, and Fig. S2 is based on ppLFER predictions. The number of compounds with COSMOtherm predictions is smaller than for the other two methods. In these plots, three intersecting lines represent each chemical. The diagonal line 

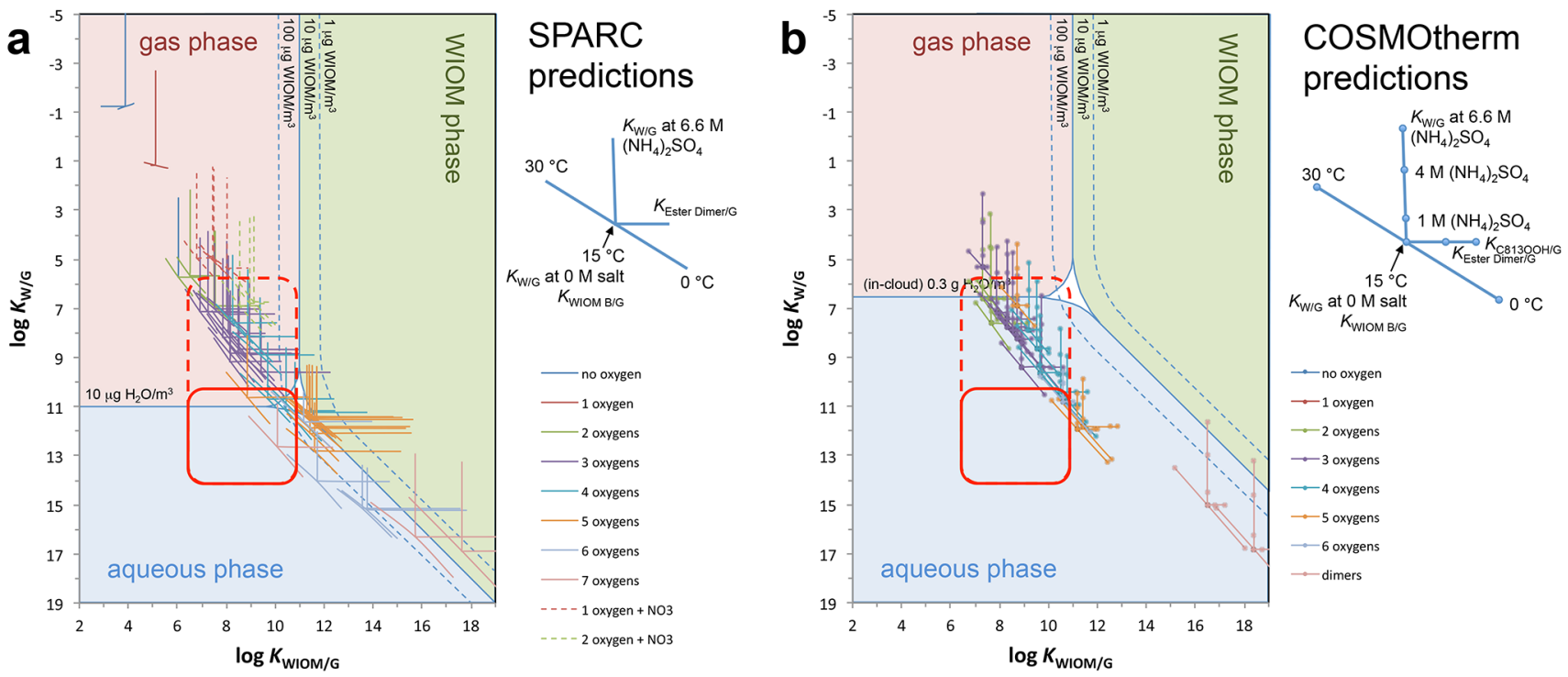

Figure 6. Placement of $\alpha$-pinene and some of its oxidation products in the chemical partitioning space based on predictions with SPARC (a) and COSMOtherm (b). Each chemical is represented by three lines, which account for the influence of temperature variations between 0 and $30^{\circ} \mathrm{C}$ (diagonal line), the salting-out effect by $6.6 \mathrm{M}\left(\mathrm{NH}_{4}\right)_{2} \mathrm{SO}_{4}$ (vertical line) and the polarity of the surrogate representing the solvation properties of WIOM (horizontal line). The chemicals are superimposed on the dominant phase distribution maps for wet aerosol (a) and a cloud (b). The red lines encircle regions where chemicals fall whose contribution to SOA formation would not be considered if the aqueous phase in an aerosol (solid line) or cloud (dashed line) were ignored.

indicates the variability in the partition coefficients caused by temperature (upper left of the line is for $30^{\circ} \mathrm{C}$; lower right is for $0^{\circ} \mathrm{C}$ ). The vertical line designates the salting-out effect, which yields a decrease in $K_{\mathrm{W} / \mathrm{G}}$. The uppermost value on that line indicates the $K_{\mathrm{W} / \mathrm{G}}$ in a $6.6 \mathrm{M}$ supersaturated solution of $\left(\mathrm{NH}_{4}\right)_{2} \mathrm{SO}_{4}$. The horizontal line indicates the range of $K_{\mathrm{WIOM} / \mathrm{G}}$ obtained by using different surrogate molecules to represent the WIOM phase (Fig. 6). In the case of the ppLFER-based plot (Fig. S2), the horizontal line indicates the range of values obtained by applying ppLFER equations for four different aerosols. Where the three lines intersect are the partition coefficients at $15^{\circ} \mathrm{C}$ and at $0 \mathrm{M}\left(\mathrm{NH}_{4}\right)_{2} \mathrm{SO}_{4}$ using structure $\mathrm{B}$ as a surrogate for WIOM (Fig. 6) or the average of the four ppLFER-predicted $K_{\text {WIOM/G }}$ (Fig. S2). An arrow plot (Fig. S3) further displays the discrepancy between the three sets of predictions at $15^{\circ} \mathrm{C}$ and $0 \mathrm{M}$.

The lines are coloured based on the number of oxygens in the molecules, ranging from 0 ( $\alpha$-pinene itself) to 7 (a highly oxygenated product listed by Valorso et al., 2011). Dashed lines designate nitrated molecules. The $\alpha$-pinene oxidation products fall along a band from the upper left ( $\alpha$-pinene itself) to the lower right (highly oxygenated products as well as dimers) of the partitioning space. Oxidation products with the same number of oxygens tend to cluster together within the partitioning space.

Differences between the prediction methods overall seem quite random and not biased (the arrows in Fig. S3 point in all sorts of directions). However, for the oxidation prod- ucts with five or more oxygens, the blue arrows point mostly to the upper right, i.e. the ppLFER predictions of $K_{\text {WIOM/G }}$ appear to be generally biased low relative to SPARC predictions and the $K_{\mathrm{W} / \mathrm{G}}$ values appear to be biased high, i.e. ppLFER predictions favour the aqueous over the WIOM phase. For three compounds $(\mathrm{C} 108 \mathrm{OOH}, \mathrm{C} 813 \mathrm{OOH}$, C721CHO), the ppLFER-predicted $K_{\mathrm{W} / \mathrm{G}}$ is much lower than the COSMOtherm-predicted one (by 4.5 to 5.5 orders of magnitude), further suggesting that ppLFERs are unduly favouring the aqueous phase. It is possible that the highly functionalised $\alpha$-pinene products fall outside the domain of applicability of the ppLFER equations (especially for $K_{\mathrm{W} / \mathrm{G}}$ ) and we therefore disregard the predictions displayed in Fig. S2 in the further discussion.

It is readily apparent from Fig. 6 that environmental variability in temperature, aqueous-phase salinity and WIOMphase polarity can have a strong impact on the partitioning properties of the SOA compounds and therefore the placement within the partitioning space. Comparison of the length of the lines in Fig. S3 with those in Fig. 6 suggests that, in most cases, the effect of environmental parameter variability on chemical placement is larger than that caused by prediction uncertainty. The length of the diagonal lines indicates that temperature differences of $30^{\circ} \mathrm{C}$ can change both $K_{\text {W/G }}$ and $K_{\text {WIOM/G }}$ by orders of magnitude, and the length of the vertical line demonstrates that salting-out can have a similarly large effect on $K_{\mathrm{W} / \mathrm{G}}$. COSMOtherm and SPARC disagree to what extent phase polarity affects $K_{\mathrm{WIOM} / \mathrm{G}}$ : 
whereas the long horizontal lines in Fig. 6a mean that SPARC predicts that $K_{\mathrm{WIOM} / \mathrm{G}}$ of the $\alpha$-pinene oxidation products increases substantially if the WIOM phase is more polar (i.e. when the surrogate solvent is changed from structure $\mathrm{B}$ to ESTER_dimer or $\mathrm{C} 813 \mathrm{OOH})$, the much shorter horizontal lines in Fig. 6b (and Fig. S2) indicate that COSMOtherm (and ppLFERs) predict a much more modest influence of phase polarity.

A more explicit comparison of $K_{\mathrm{WIOM} / \mathrm{G}}$ values obtained for different surrogate solvents (Fig. S4) shows that SPARC and COSMOtherm actually agree that the solvation properties of C813OOH and ESTER_dimer should be similar. They disagree, however, to what extent the solvation properties of these two more polar surrogates deviate from those of structure B of Kalberer et al. (2004). The length of the horizontal lines in Fig. 6a would imply that the activity coefficients of the compounds in different organic solvents can vary by as much as 4 orders of magnitude, which is not very plausible. The SPARC predictions for the highly polar solvents should therefore be considered suspect, also because SPARC may fail to accurately predict partitioning into organic phases for which few empirical data for calibration are available (Stenzel et al., 2014).

The various predictions, however, agree in many other regards - for example with respect to the effect of temperature. Lower temperatures always shift chemical distribution to the condensed phases, and the temperature effect on $K_{\mathrm{W} / \mathrm{G}}$ and $K_{\mathrm{WIOM} / \mathrm{G}}$ is similar (i.e. the temperature lines in Fig. 6 are more or less parallel to the line designating the transition between dominant partitioning into WIOM and aqueous phase). The only exceptions are the most volatile species, such as $\alpha$-pinene itself, where a drop in temperature actually leads to a small decrease in $K_{\mathrm{W} / \mathrm{G}}$. The partition coefficients become more temperature-dependent as they increase, i.e. the lines for the least volatile chemicals in the lower right are the longest. This implies that the effect of temperature on partitioning is stronger for the higher-generation oxidation products and is due to the well-known linear correlation between the logarithm of a partition coefficient and the enthalpy of phase transfer (Goss and Schwarzenbach, 1999). The vertical lines, on the other hand, decrease in length with increasing oxygenation, i.e. the salting-out effect is weaker for the higher-generation oxidation products. This is because Setschenow coefficients are smaller for more polar substances (Endo et al., 2012; Wang et al., 2014).

By comparing the placement of chemicals in Fig. 6 with the boundaries of dominant phase distribution introduced in Fig. 1, we can graphically predict the phase distribution behaviour of $\alpha$-pinene oxidation products under different conditions (Fig. 6a and b display the boundaries for LWC typical for aerosol and clouds, respectively). At the low LWC typical of aerosol (Fig. 6a), products with four oxygen atoms are starting to contribute to the condensed phase, especially at higher OALs and lower temperature. Products with five or more oxygen atoms are already predicted to have only mi- nor fractions in the gas phase, falling close to the boundary between aqueous and WIOM phase. The salting-out effect likely assures that those $\alpha$-pinene oxidation products would be found mostly in the WIOM phase. Products with seven or more oxygen atoms (i.e. the ELVOCs observed as major products of $\alpha$-pinene oxidation in the field by Ehn et al., 2014) would clearly no longer be in the gas phase under any conditions.

The partitioning space analysis also suggests that, under the high-LWC conditions typical of a cloud (Fig. 6b), oxidation products of $\alpha$-pinene with three or even only two oxygens would partition strongly into the aqueous condensed phase, also because the salting-out effect would no longer be active. This incidentally highlights why an analysis of phase partitioning that ignores liquid water in the atmosphere can lead to erroneous conclusions, especially in the presence of clouds. The red outlines in Fig. $6 \mathrm{a}$ and $\mathrm{b}$ designate the region where chemicals fall whose contribution to SOA formation would not be taken into account if the aqueous phase were ignored. At low LWC typical of aerosol (solid red outline), this applies to few, if any, oxidation products; however at high LWC typical of clouds (dashed red outline), a very large number of oxidation products would remain in the gas phase. This appears to be in agreement with Pankow et al. (2013), who predict "significant RH-induced enhancement of organic particulate matter condensation" in the $\alpha$ pinene-ozone system.

Incidentally, none of the $\alpha$-pinene oxidation products are predicted to partition notably into WIOM at high LWC typical of clouds (Fig. 6b). This probably means that, unless there is another source of WIOM to the atmosphere, a single, mostly aqueous aerosol phase would form under such conditions.

We stress that there are other reasons why a chemical's location may depend on environmental conditions. For example, some SOA compounds are acids with $p K_{\mathrm{A}}$ values in the $\mathrm{pH}$ range encountered in the aqueous phase of aerosol and cloud droplets, i.e. they can be expected to be ionised to some degree. Ionisation increases $K_{\mathrm{W} / \mathrm{G}}$ relative to the value that is estimated by the prediction methods for the protonated form of the acids. It also means that $K_{\mathrm{W} / \mathrm{G}}$, and therefore the placement in the partitioning space, depends on the $\mathrm{pH}$ of the aqueous phase.

\subsection{Illustrating displacement within the partitioning space caused by chemical transformations}

So far, the SOA compounds have been considered in isolation and not as part of a chemical reaction sequence. Figure 7 shows the oxidation products of the $\mathrm{C} 17 n$-alkane linked by arrows designating the chemical reactions elucidated by Lim and Ziemann (2005). Like the $\alpha$-pinene oxidation products in Fig. 6, the oxidation products fall along a band that starts at the precursor VOC in the upper left and extends to the lower right of the partitioning space. Remarkably, the slope 


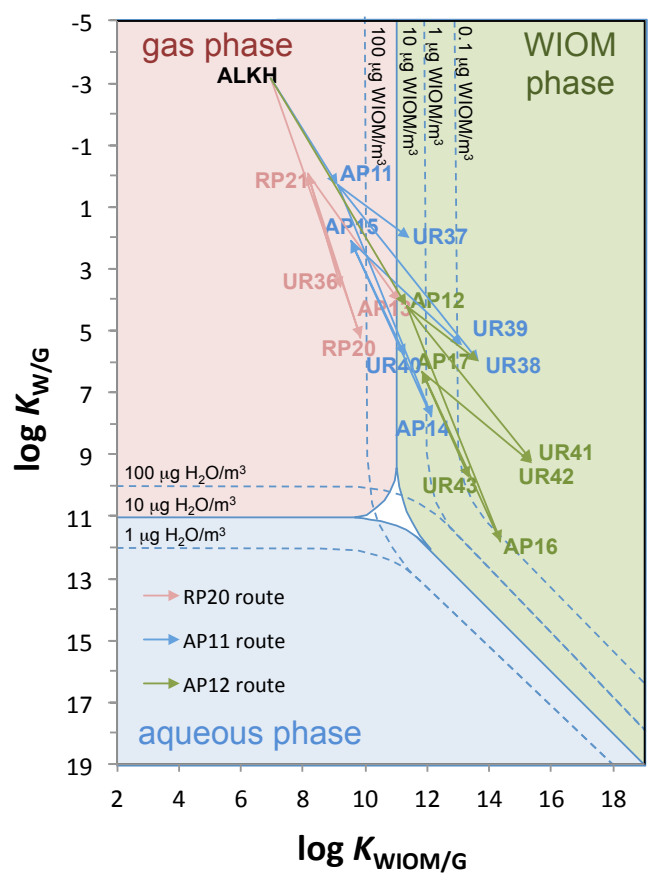

Figure 7. Oxidation products of the $n$-alkane with 17 carbon atoms placed within the chemical partitioning space based on partition coefficients at $25^{\circ} \mathrm{C}$ predicted with ppLFERs and connected by arrows based on sequence of reaction by which they are formed. The code names for the compounds are based on Jordan et al. (2008).

of that band and even the extent of its broadening toward the lower right is very similar for C17 (and by inference all $n$-alkanes) and $\alpha$-pinene. This similarity is not really surprising, as in both cases hydroxyl, carbonyl, peroxyl, nitrate and carboxylic acid functional groups are being added to an aliphatic compound. Hodzic et al. (2014) also noted that the relationships between effective Henry's law constant and saturation concentration were similar for the products of different precursors.

The slope of these bands of compounds within the partitioning space suggests that, on average, such functionalisation roughly increases the $K_{\mathrm{W} / \mathrm{G}}$ by two $\log$ units for every $\log$ unit increase in $\log K_{\mathrm{WIOM} / \mathrm{G}}$, i.e. the addition of functional groups increases the affinity for the aqueous phase more rapidly than the affinity for the WIOM phase. Incidentally, this is different from what Hodzic et al. (2014) noted for the oxidation products of different precursors: for a one log unit change in saturation concentration, the effective Henry's law constant only changed by 0.5 to $0.9 \log$ units. Whether the functionalisation of a precursor VOC ends up generating compounds that prefer the WIOM or the aerosol aqueous phase depends to some extent on the location of that precursor in the partitioning space. The lower the $K_{\mathrm{W} / \mathrm{G}}$ and the higher the $K_{\mathrm{WIOM} / \mathrm{G}}$ of a precursor, the more likely it is to generate oxidation products that favour the WIOM phase.
The broadening of the band is due to different changes in $K_{\text {W/G }}$ and $K_{\text {WIOM/G }}$ occurring upon the addition of different functional groups. According to Lim and Ziemann (2005), the first few steps of the oxidation of $n$-alkanes by $\mathrm{OH}$ in the presence of $\mathrm{NO}_{\mathrm{x}}$ involve primarily five types of transformations. The displacement within the partitioning space caused by these transformations is depicted in Fig. 8 .

As expected from the general trend toward the lower right seen in Fig. 7, the addition of functional groups to the aliphatic chain increases both $K_{\mathrm{WIOM} / \mathrm{G}}$ and $K_{\mathrm{W} / \mathrm{G}}$, i.e. arrows pointing to the lower right represent the reaction steps. The exception is the formation of cyclical dihydrofurans from $\delta$-hydroxycarbonyls, which leads to a displacement in the opposite direction, i.e. to a more volatile substance. The size and direction of the displacement in the partitioning space depends on the functional groups being added. The addition of oxygen-containing groups such as hydroxyl, carbonyl and carboxylester increases $K_{\mathrm{W} / \mathrm{G}}$ more than $K_{\mathrm{WIOM} / \mathrm{G}}$, i.e. the mean vertical displacement is generally more than double the mean horizontal displacement. The addition of nitrate, on the other hand, leads to about equal displacement in the vertical and horizontal direction, i.e. causes $K_{\mathrm{W} / \mathrm{G}}$ and $K_{\mathrm{WIOM} / \mathrm{G}}$ to increase to the same extent. This incidentally explains why nitrated compounds (represented by broken lines in Fig. 6a) and especially dinitrated compounds (UR37, UR38, UR39, UR41, UR42 in Fig. 7) tend to fall on the right side of the band of oxidation products, whereas those without nitrate substitutions (RP20, RP21, UR36 in Fig. 7) fall on the left. This implies that nitration increases the affinity for WIOM more than the addition of carbonyls, hydroxyls and carboxylester does. This is in agreement with Hodzic et al. (2014), who noted that products formed during low- $\mathrm{NO}_{\mathrm{x}}$ conditions are predicted to be more soluble.

To which compound a functional group is being added often does not seem to matter much (i.e. the arrows within each panel of Fig. 8 are of similar length and point in a similar direction). In particular the alkyl-chain length plays a limited role (blue and green arrows are very similar). However, the displacement caused by the addition of nitrate is different for different compounds. For example, nitration of the dihydrofuran leads to a larger change in $K_{\mathrm{WIOM} / \mathrm{G}}$ and $K_{\mathrm{W} / \mathrm{G}}$ (longer arrows) than nitration of the aliphatic chain. The addition of a second nitrate leads to a smaller increase in $K_{\mathrm{W} / \mathrm{G}}$ (arrows point more to the right) than the first nitrate.

To obtain a broader set of displacements caused by chemical transformations, we also looked at the functionalisation occurring during oxidation of aromatic hydrocarbons (Fig. S5). This analysis confirmed that the addition of oxygen-containing functional groups again increases both $K_{\mathrm{WIOM} / \mathrm{G}}$ and $K_{\mathrm{W} / \mathrm{G}}$, with the latter increasing more rapidly, i.e. the vertical displacement being slightly larger than the horizontal one. The displacement is increasing from carbonyl to hydroxyl to carboxyl groups (i.e. arrows are getting longer in Fig. S5), whereby the sum of the displacements caused by 
a carbonyl and a hydroxyl group is larger than the displacement caused by the addition of a carboxyl group. Similar to the addition of a nitrate group to the $n$-alkane oxidation products (Fig. 8), the addition of a nitro group to a mono-aromatic hydrocarbon increases $K_{\mathrm{WIOM} / \mathrm{G}}$ and $K_{\mathrm{W} / \mathrm{G}}$ to the same extent, i.e. horizontal and vertical displacements are very similar (Fig. S5). Increasing the size of a mono-aromatic compound through the addition of methyl and methylene groups has only a very minor effect on the placement in the partitioning space, increasing $K_{\mathrm{WIOM} / \mathrm{G}}$ only slightly and $K_{\mathrm{W} / \mathrm{G}}$ hardly at all (Fig. S5).

In the case of $-\mathrm{OH}$ and $-\mathrm{NO}_{2}$ addition to a mono-aromatic hydrocarbon, the displacement in the partitioning space can be strongly dependent on the type of functional groups already present in the molecule. The difference in the change in $K_{\mathrm{WIOM} / \mathrm{G}}$ and $K_{\mathrm{W} / \mathrm{G}}$ occurring upon the addition of $-\mathrm{OH}$ directly to the aromatic ring or to an existing carbonyl group (i.e. conversion of benzaldehyde to benzoic acid) is relatively small (Fig. 9a). On the other hand, the effect on partitioning upon the addition of $-\mathrm{OH}$ is much diminished if the hydroxyl can form intramolecular hydrogen bonds with an existing carbonyl or nitro group (Fig. 9a). The widely different shift in the partitioning space occurring upon the addition of a nitro group (Fig. 9b) further confirms that it is not merely the presence of existing polar functional groups in the molecules that matters but whether those functional groups are in a position to form intramolecular hydrogen bonds with the $-\mathrm{NO}_{2}$. For example, SPARC predicts that the addition of $-\mathrm{NO}_{2}$ at the ortho-position to an existing - $\mathrm{OH}$ hardly changes the partitioning properties at all, whereas addition at the para-position increases both $K_{\mathrm{WIOM} / \mathrm{G}}$ and $K_{\mathrm{W} / \mathrm{G}}$ by more than 3 orders of magnitude (Fig. 9b).

So far, we have only considered transformations that lead to functionalisation of an aliphatic or aromatic carbon structure. Dimerisation reactions in the condensed phase are also believed to play a role in SOA formation. Figure 10 shows the displacements caused by various dimerisation reactions proposed for the ozonolysis reaction products of $\alpha$-pinene by Camredon et al. (2010). The partition coefficients of both monomers and dimers at $15^{\circ} \mathrm{C}$ in this plot were estimates with SPARC, although it is possible that the very large dimer molecules fall outside of the domain of applicability of SPARC.

Dimer formation increases both $K_{\mathrm{WIOM} / \mathrm{G}}$ and $K_{\mathrm{W} / \mathrm{G}}$ and thus leads to a displacement to the lower right (Fig. 10). The overall effect of dimerisation is the conversion of semivolatile organic compounds into low and extremely low volatility compounds. The extent and the direction of displacement appear to depend on the type of reaction, with hemiacetal and peroxyhemiacetal formation causing the largest overall displacement (longest arrows in Fig. 10) and the largest increase in $K_{\mathrm{W} / \mathrm{G}}$ relative to $K_{\mathrm{WIOM} / \mathrm{G}}$ (steepest incline of the arrows in Fig. 10). Most dimerisations, however, are predicted to increase $K_{\mathrm{WIOM} / \mathrm{G}}$ and $K_{\mathrm{W} / \mathrm{G}}$ to the same extent.

\section{Conclusions and discussion}

One main application of the chemical partitioning space maps introduced here is the possibility to visualise and therefore easily compare the impact of a wide variety of factors on SOA formation. For example, it allows for a direct comparison of the uncertainty of the prediction of partition coefficients with the impact of atmospheric variability on these coefficients. It facilitates a comparison of the direction and size of the effects of temperature, salinity and organic-phase polarity on the partitioning behaviour of different SOA compounds. The change in partitioning behaviour occurring upon dimerisation can be compared with that of adding a hydroxyl or a nitrate functional group. Because everything is displayed within the same two-dimensional framework, even very different factors can be assessed comparatively: prediction uncertainty can be compared with the effect of a change in OAL or LWC on partitioning, the effect of a chemical reaction, or the effect of a change in temperature and ammonium sulfate concentration.

This suitability for comparative visualisation can serve to aid in the understanding of dynamic processes, where several of the factors affecting phase distribution are changing at the same time. For example, during a photochemical smog episode, or during a chamber experiment, the precursor VOCs become oxidised, and with increasing functionalisation - and eventually also dimerisation - the oxidation products partition increasingly into the condensed phase (i.e. they move to the lower right of the partitioning space) (Fig. 11). As a result, the OAL is increasing, causing the vertical threshold that separates dominant phase distribution into gas and WIOM phase to move to the left (Fig. 11). This implies that, with ongoing SOA formation, more and more volatile chemicals become available for partitioning to the WIOM. Overall, the changes in partitioning behaviour caused by the chemical processes are considerably larger than the shift in the threshold caused by the increase in OAL (Fig. 11).

Similarly, during cloud droplet formation a large upward shift in the horizontal threshold between dominant phase distribution into water and gas phase coincides with a downward shift in the position of SOA compounds in the partitioning space, as salts become diluted and the salting-out effect becomes negligible. Another example is the dilution of tail pipe emissions, which is accompanied by a rapid decrease in both OAL and temperature, having opposing effects on the partitioning between gas and WIOM phase (May et al., 2013).

Another application of the partitioning space is the identification and prioritisation of data gaps. The maps graphically highlight the factors and effects that matter and for which compounds they matter. They provide guidance to distinguish processes and parameters that need to be known more accurately and more precisely from those with tolerable uncertainty. For example, there is little to be gained from improved quantitative knowledge of the partitioning properties 

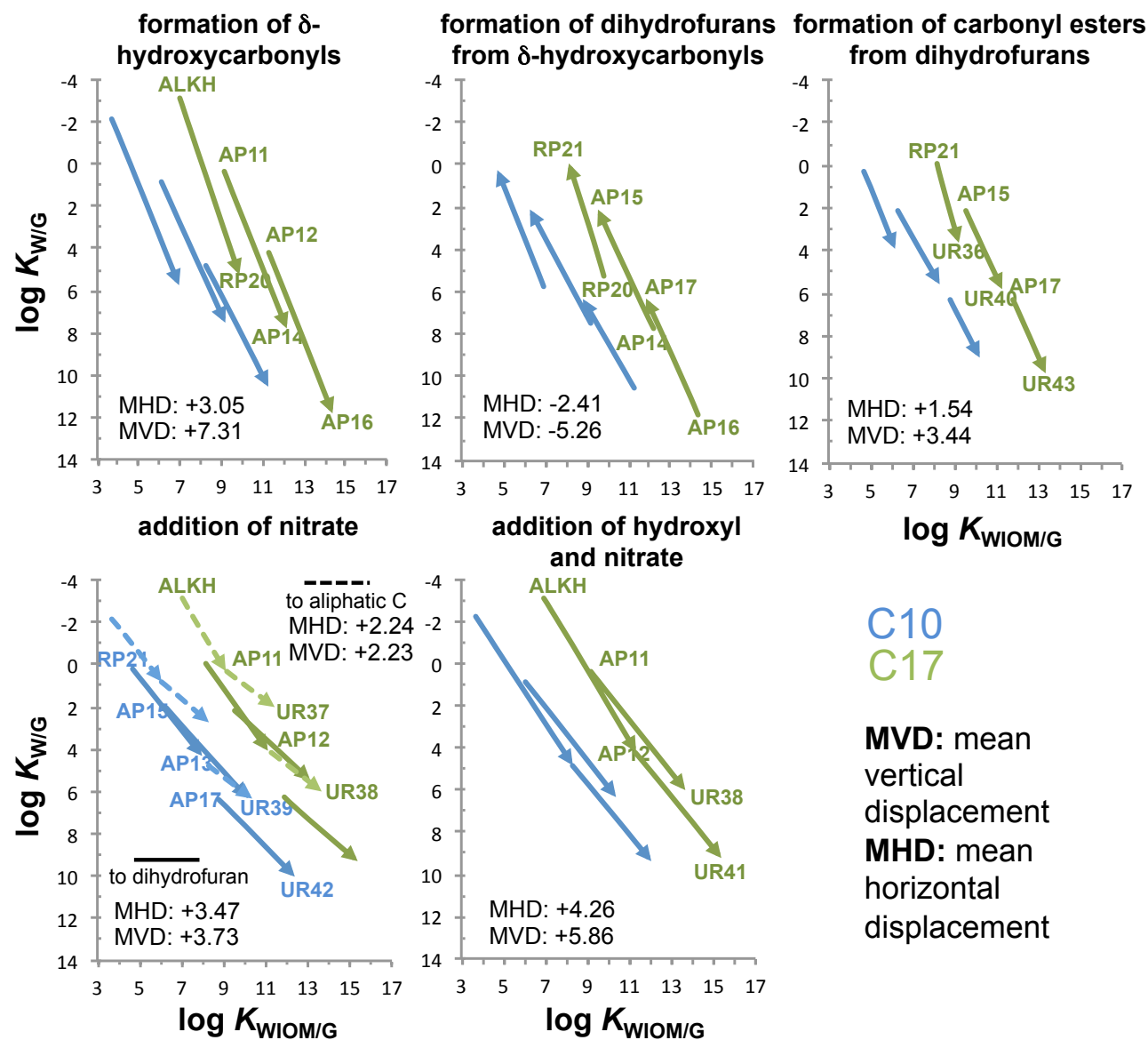

C10

MVD: mean

vertical

displacement

MHD: mean

horizontal

displacement

Figure 8. Displacement of chemicals in the partitioning space caused by transformations involved in the oxidation of $n$-alkanes with 10 (blue) and 17 (green) carbons using predictions of $K_{\mathrm{WIOM} / \mathrm{G}}$ and $K_{\mathrm{W} / \mathrm{G}}$ at $25^{\circ} \mathrm{C}$ obtained by ppLFER. Also given are the mean vertical displacement (MVD) and mean horizontal displacement (MHD).
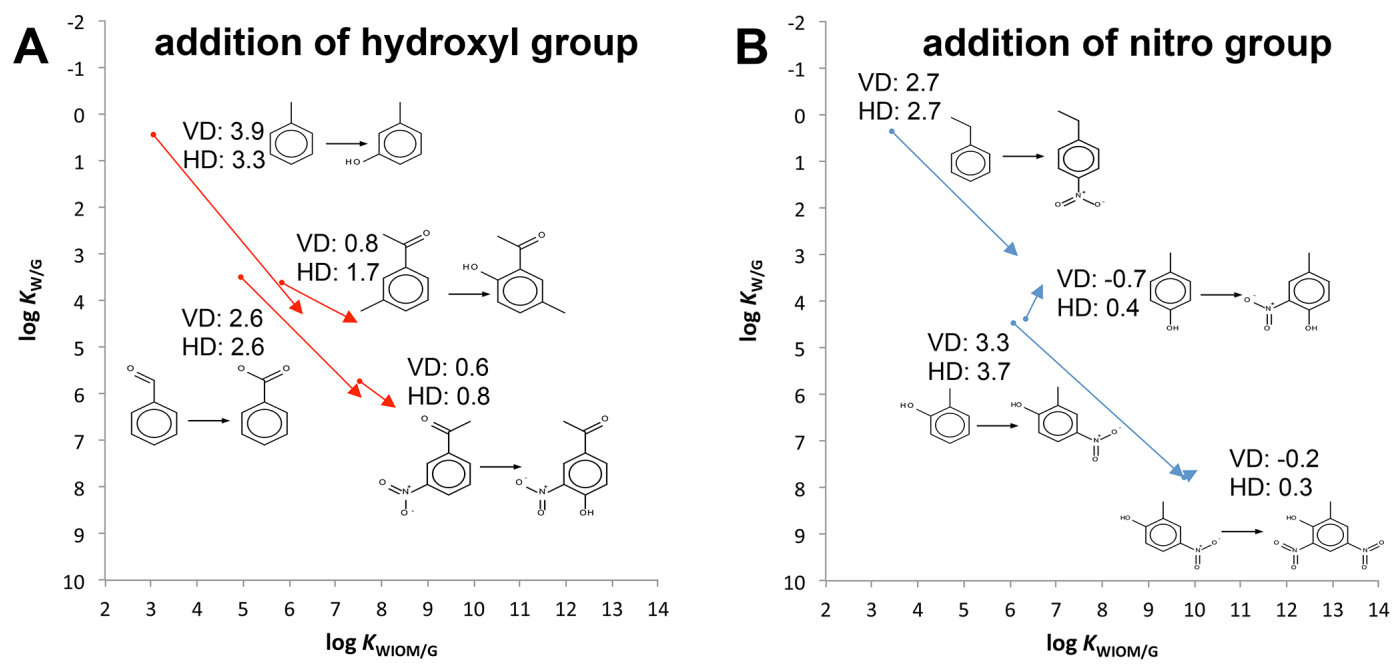

Figure 9. Displacement in the chemical partitioning space occurring upon the addition of a hydroxyl (a) or nitro (b) group to a mono-aromatic hydrocarbon, as predicted by SPARC for $15^{\circ} \mathrm{C}$ and using structure B for WIOM (VD: vertical displacement; HD: horizontal displacement). 


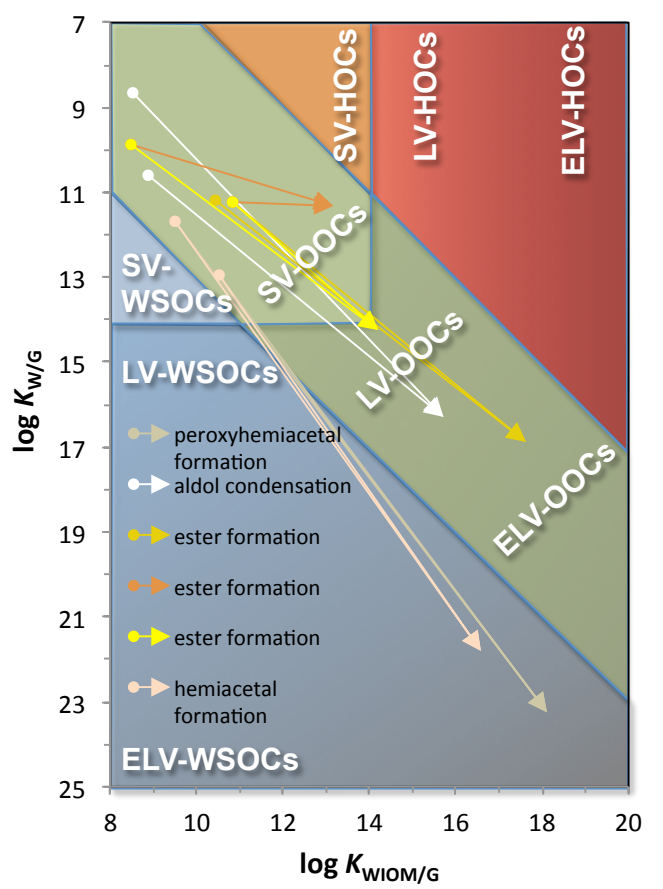

Figure 10. Displacements in the chemical partitioning space due to various dimerisation reactions proposed for ozonolysis reaction products of $\alpha$-pinene by Camredon et al. (2010). $K_{\mathrm{WIOM} / \mathrm{G}}$ and $K_{\mathrm{W} / \mathrm{G}}$ at $15^{\circ} \mathrm{C}$ were estimates with SPARC using structure B as a surrogate for WIOM. Also shown is the categorisation into compounds with different atmospheric phase distribution behaviour introduced in Fig. 4.

of VOCs and ELVOCs. On the other hand, resolving the disagreement of the prediction methods with respect to the size of the effect of WIOM-phase polarity on $K_{\text {WIOM/G }}$ should be a priority. Also important is improving quantitative knowledge of $K_{\mathrm{W} / \text { WIOM }}$ and Setschenow coefficients $\left(K_{\mathrm{S}}\right)$ of the SV-OOCs and LV-OOCs and of $K_{\mathrm{W} / \mathrm{G}}$ and $K_{\mathrm{S}}$ of substances falling in the red outlines of Fig. 6.

The chemical partitioning plots provide a new integrated perspective that looks at the formation of WIOM- and aqueous-phase SOA at the same time. The plots suggest that many oxidation products (including dimers formed by condensed phase reactions) fall into the transition area between WIOM and aqueous phase in the lower right of the partitioning space. This is because the WIOM- and aqueous-phase volumes are actually quite similar (LWC and OAL are within the same order of magnitude under clear cloud conditions) and because the highly functionalised oxidation products are predicted to have a reasonably similar affinity for WIOM and water (i.e. $0.01<K_{\mathrm{WIOM} / \mathrm{W}}<100$ ). Often it may be the presence of inorganic salts and the resulting salting-out effect that decides whether an SOA compound will be in the WIOM or aqueous phase. Temperature, incidentally, will have little direct impact in this regard, because $K_{\text {WIOM/W }}$ is hardly dependent on temperature (the lines in Fig. 6 are parallel

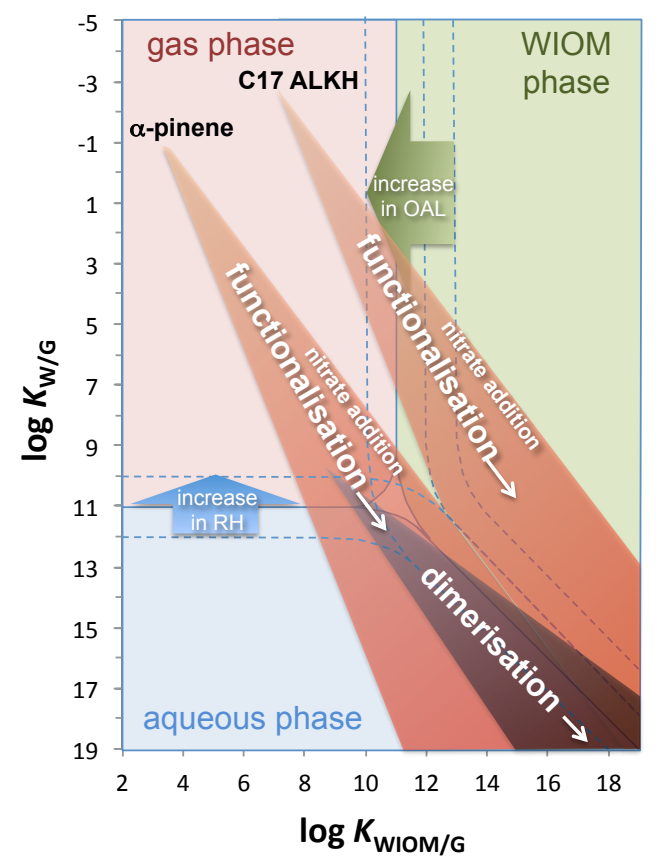

Figure 11. Visualisation in the partitioning space of processes occurring during the oxidation of VOC precursors in a chamber experiment or a photochemical smog episode (in the presence of water). While the addition of functional groups and dimerisation reactions lead to an increase in $K_{\mathrm{WIOM} / \mathrm{G}}$ and $K_{\mathrm{W} / \mathrm{G}}$ and therefore a gradual shift to the lower right, the attendant increase in the organic aerosol load shifts the threshold for the gas-WIOM transition to the left.

to the dividing line between dominant phase distribution to WIOM and aqueous phase). Temperature changes, of course, impact relative humidity and thus LWC and can have an indirect effect on the distribution between WIOM and water. Does it matter whether an oxidation product is in the WIOM or the aqueous phase, as long as it is contributing to the OAL? The relative volumes of WIOM and aqueous phase vary in the atmosphere. For example, the liquid water content in wet aerosol is regionally different, driven largely by sulfate concentrations (Carlton et al., 2013). Therefore, partitioning between the two condensed phases and the value of $K_{\text {W/WIOM }}$ is important for predicting SOA formation, composition and yield. Also, the occurrence and kinetics of condensed phase reactions that oxidation products may undergo, such as dimerisations or reactions with sulfate, are likely to be different in the WIOM and aqueous phase.

Several two-dimensional property spaces have been advocated for describing organic aerosol characteristics (Pankow and Brasanti, 2009; Kroll et al., 2011; Cappa and Wilson, 2012), the 2-D VBS by Donahue et al. $(2011,2012)$ using saturation concentration and $\mathrm{O}: \mathrm{C}$ ratio $\left(\right.$ or $\mathrm{OS}_{\mathrm{C}}$ ) being the most conspicuous. One of the key shortcomings of the 2-D VBS approach is that it "does not allow consideration of water uptake or variable partition coefficients" (Pankow et al., 2013). Donahue et al. (2012) actually mention this when in- 
troducing the 2-D VBS: "The formulation so far does not address the role of water. ... However, because water can be a dominant component, and therefore its unique properties are more likely to challenge the mean-field assumption, it is likely that explicit treatment of humidity effects will be required." Here we have presented what essentially amounts to an alternative two-dimensional approach to SOA characterisation based on partition coefficients from gas phase into WIOM and water. This approach includes partitioning into an aqueous phase and directly addresses one of the key issues that atmospheric modellers of SOA formation aim to address: which fraction of the products formed from the oxidation of VOCs will end up in the SOA after equilibration under different atmospheric conditions. We could imagine that it is possible to develop parameterisations of the chemical partitioning space introduced here which - combined with gas-phase concentrations of sets of compounds with comparable partitioning properties - are suitable for implementation in atmospheric models seeking to explicitly describe the formation of SOA.

\section{The Supplement related to this article is available online at doi:10.5194/acp-15-3395-2015-supplement.}

Acknowledgements. The authors acknowledge financial support from the Natural Sciences and Engineering Research Council of Canada (NSERC).

Edited by: A. Carlton

\section{References}

Arp, H. P. H. and Goss, K. U.: Ambient gas/particle partitioning. 3. Estimating partition coefficients of apolar, polar, and ionizable organic compounds by their molecular structure, Environ. Sci. Technol., 43, 1923-1929, 2009.

Arp, H. P. H., Schwarzenbach, R. P., and Goss, K. U.: Ambient gas/particle partitioning. 2: The influence of particle source and temperature on sorption to dry terrestrial aerosols, Environ. Sci. Technol., 42, 5951-5957, 2008.

Bertram, A. K., Martin, S. T., Hanna, S. J., Smith, M. L., Bodsworth, A., Chen, Q., Kuwata, M., Liu, A., You, Y., and Zorn, S. R.: Predicting the relative humidities of liquid-liquid phase separation, efflorescence, and deliquescence of mixed particles of ammonium sulfate, organic material, and water using the organic-to-sulfate mass ratio of the particle and the oxygen-tocarbon elemental ratio of the organic component, Atmos. Chem. Phys., 11, 10995-11006, doi:10.5194/acp-11-10995-2011, 2011.

Camredon, M., Hamilton, J. F., Alam, M. S., Wyche, K. P., Carr, T., White, I. R., Monks, P. S., Rickard, A. R., and Bloss, W. J.: Distribution of gaseous and particulate organic composition during dark $\alpha$-pinene ozonolysis, Atmos. Chem. Phys., 10, 2893-2917, doi:10.5194/acp-10-2893-2010, 2010.
Cappa, C. D. and Wilson, K. R.: Multi-generation gas-phase oxidation, equilibrium partitioning, and the formation and evolution of secondary organic aerosol, Atmos. Chem. Phys., 12, 9505-9528, doi:10.5194/acp-12-9505-2012, 2012.

Carlton, A. G. and Turpin, B. J.: Particle partitioning potential of organic compounds is highest in the Eastern US and driven by anthropogenic water, Atmos. Chem. Phys., 13, 10203-10214, doi:10.5194/acp-13-10203-2013, 2013.

Chen, J. J. and Griffin, R. J.: Modeling secondary organic aerosol formation from oxidation of alpha-pinene, beta-pinene, and dlimonene, Atmos. Environ., 39, 7731-7744, 2005.

Ehn, M., Thornton, J. A., Kleist, E., Sipilä, M., Junninen, H., Pullinen, I., Springer, M., Rubach, F., Tillmann, R., Lee, B., LopezHilfiker, F., Andres, S., Acir, I.-H., Rissanen, M., Jokinen, T., Schobesberger, S., Kangasluoma, J., Kontkanen, J., Nieminen, T., Kurtén, T., Nielsen, L. B., Jørgensen, S., Kjaergaard, H. G., Canagaratna, M., Dal Maso, M., Berndt, T., Petäjä, T., Wahner, A., Kerminen, V.-M., Kulmala, M., Worsnop, D. R., Wildt, J., and Mentel, T. F.: A large source of low-volatility secondary aerosol, Nature, 506, 476-479, 2014.

Endo, S., Pfennigsdorff, A., and Goss, K.-U.: Salting-out effect in aqueous $\mathrm{NaCl}$ solutions: Trends with size and polarity of solute molecules, Environ. Sci. Technol., 46, 1496-1503, 2012.

Donahue, N. M., Robinson, A. L., Stanier, C. O., and Pandis, S. N.: Coupled partitioning, dilution, and chemical aging of semivolatile organics, Environ. Sci. Technol., 40, 2635-2643, 2006.

Donahue, N. M., Epstein, S. A., Pandis, S. N., and Robinson, A. L.: A two-dimensional volatility basis set: 1. organic-aerosol mixing thermodynamics, Atmos. Chem. Phys., 11, 3303-3318, doi:10.5194/acp-11-3303-2011, 2011.

Donahue, N. M., Kroll, J. H., Pandis, S. N., and Robinson, A. L.: A two-dimensional volatility basis set - Part 2: Diagnostics of organic-aerosol evolution, Atmos. Chem. Phys., 12, 615-634, doi:10.5194/acp-12-615-2012, 2012.

Forstner, H. J. L., Flagan, R. C., and Seinfeld, J. H.: Secondary organic aerosol from the photooxidation of aromatic hydrocarbons: molecular composition, Environ. Sci. Technol., 31, 1345-1358, 1997.

Goss, K.-U. and Schwarzenbach, R. P.: Empirical prediction of heats of vaporization and heats of adsorption of organic compounds, Environ. Sci. Technol., 33, 3390-3393, 1999.

Goss, K.-U.: Prediction of the temperature dependency of Henry's law constant using poly-parameter linear free energy relationships, Chemosphere, 64, 1369-1374, 2006.

Hallquist, M., Wenger, J. C., Baltensperger, U., Rudich, Y., Simpson, D., Claeys, M., Dommen, J., Donahue, N. M., George, C., Goldstein, A. H., Hamilton, J. F., Herrmann, H., Hoffmann, T., Iinuma, Y., Jang, M., Jenkin, M. E., Jimenez, J. L., Kiendler-Scharr, A., Maenhaut, W., McFiggans, G., Mentel, Th. F., Monod, A., Prévôt, A. S. H., Seinfeld, J. H., Surratt, J. D., Szmigielski, R., and Wildt, J.: The formation, properties and impact of secondary organic aerosol: current and emerging issues, Atmos. Chem. Phys., 9, 5155-5236, doi:10.5194/acp-9-51552009, 2009.

Heald, C. L., Kroll, J. H., Jimenez, J. L., Docherty, K. S., DeCarlo, P. F., Aiken, A. C., Chen, Q., Martin, S. T., Farmer, D. K., and Artaxo, P.: A simplified description of the evolution of organic 
aerosol composition in the atmosphere, Geophys. Res. Lett., 37, L08803, doi:10.1029/2010GL042737, 2010.

Hilal, S. H., Carreira, L. A., and Karickhoff, S. W.: Prediction of the solubility, activity coefficient, gas/liquid and liquid/liquid distribution coefficients of organic compounds, QSAR \& Combinatorial Science, 23, 709-720, 2004.

Hodzic, A., Aumont, B., Knote, C., Madronich, S., and Tyndall, G.: Volatility dependence of Henry's law constants of condensable organics: Application to estimate depositional loss of secondary organic aerosols, Geophys. Res. Lett., 41, 4795-4804, doi:10.1002/2014GL060649, 2014.

Ip, H. S. S., Huang, X. H. H., and Yu, J. Z.: Effective Henry's law constants of glyoxal, glyoxylic acid, and glycolic acid, Geophys. Res. Lett., 36, L01802, doi:10.1029/2008GL036212, 2009.

Isaacman, G., Worton, D. R., Kreisberg, N. M., Hennigan, C. J., Teng, A. P., Hering, S. V., Robinson, A. L., Donahue, N. M., and Goldstein, A. H.: Understanding evolution of product composition and volatility distribution through in-situ GC $\times$ GC analysis: a case study of longifolene ozonolysis, Atmos. Chem. Phys., 11, 5335-5346, doi:10.5194/acp-11-5335-2011, 2011.

Jimenez, J. L., Canagaratna, M. R., Donahue, N. M., Prevot, A. S., Zhang, Q., Kroll, J. H., DeCarlo, P. F., Allan, J. D., Coe, H., Ng, N. L., Aiken, A. C., Docherty, K. S., Ulbrich, I. M., Grieshop, A. P., Robinson, A. L., Duplissy, J., Smith, J. D., Wilson, K. R., Lanz, V. A., Hueglin, C., Sun, Y. L., Tian, J., Laaksonen, A., Raatikainen, T., Rautiainen, J., Vaattovaara, P., Ehn, M., Kulmala, M., Tomlinson, J. M., Collins, D. R., Cubison, M. J., Dunlea, E. J., Huffman, J. A., Onasch, T. B., Alfarra, M. R., Williams, P. I., Bower, K., Kondo, Y., Schneider, J., Drewnick, F., Borrmann, S., Weimer, S., Demerjian, K., Salcedo, D., Cottrell, L., Griffin, R., Takami, A., Miyoshi, T., Hatakeyama, S., Shimono, A., Sun, J. Y., Zhang, Y. M., Dzepina, K., Kimmel, J. R., Sueper, D., Jayne, J. T., Herndon, S. C., Trimborn, A. M., Williams, L. R., Wood, E. C., Middlebrook, A. M., Kolb, C. E., Baltensperger, U., and Worsnop, D. R.: Evolution of organic aerosols in the atmosphere, Science, 326, 1525-1529, 2009.

Jordan, C. E., Ziemann, P. J., Griffin, R. J., Lim, Y. B., Atkinson, R., and Arey, J.: Modeling SOA formation from $\mathrm{OH}$ reactions with C-8-C-17 n-alkanes, Atmos. Environ., 42, 8015-8026, 2008.

Kalberer, M., Paulsen, D., Sax, M., Steinbacher, M., Dommen, J., Prevot, A. S. H., Fisseha, R., Weingartner, E., Frankevich, V., Zenobi, R., and Baltensperger, U.: Identification of polymers as major components of atmospheric organic aerosols, Science, 303, 1659-1662, 2004.

Kampf, C. J., Waxman, E. M., Slowik, J. G., Dommen, J., Pfaffenberger, L., Praplan, A. P., Prevot, A. S. H., Baltensperger, U., Hoffmann, T., and Volkamer, R.: Effective Henry's law partitioning and the salting constant of glyoxal in aerosols containing sulfate, Environ. Sci. Technol., 47, 4236-4244, 2013.

Koop, T., Bookhold, J., Shiraiwa, M., and Pöschl, U.: Glass transition and phase state of organic compounds: dependency on molecular properties and implications for secondary organic aerosols in the atmosphere, Phys. Chem. Chem. Phys., 13, 19238-19255, 2011.

Kroll, J. H., Donahue, N. M., Jimenez, J. L., Kessler, S. H., Canagaratna, M. R., Wilson, K. R., Altieri, K. E., Mazzoleni, L. R., Wozniak, A. S., Bluhm, H., Mysak, E. R., Smith, J. D., Kolb, C. E., and Worsnop, D. R.: Carbon oxidation state as a metric for describing the chemistry of atmospheric organic aerosol, Nature Chemistry, 3, 133-139, 2011.

Lei, Y. D. and Wania, F.: Is rain or snow a more efficient scavenger of organic chemicals?, Atmos. Environ., 38, 3557-3571, 2004.

Lim, Y. B. and Ziemann, P. J.: Products and mechanism of secondary organic aerosol formation from reactions of n-alkanes with $\mathrm{OH}$ radicals in the presence of $\mathrm{NO}_{\mathrm{x}}$, Environ. Sci. Technol., 39, 9229-9236, 2005.

Lim, Y. B., Tan, Y., Perri, M. J., Seitzinger, S. P., and Turpin, B. J.: Aqueous chemistry and its role in secondary organic aerosol (SOA) formation, Atmos. Chem. Phys., 10, 1052110539, doi:10.5194/acp-10-10521-2010, 2010.

May, A. A., Presto, A. A., Hennigan, C. J., Nguyen, N. T., Gordon, T. D., and Robinson, A. L.: Gas-particle partitioning of primary organic aerosol emissions: 1. Gasoline vehicle exhaust, Atmos. Environ., 77, 128-139, 2013.

Mikhailov, E., Vlasenko, S., Martin, S. T., Koop, T., and Pöschl, U.: Amorphous and crystalline aerosol particles interacting with water vapor: conceptual framework and experimental evidence for restructuring, phase transitions and kinetic limitations, Atmos. Chem. Phys., 9, 9491-9522, doi:10.5194/acp-9-9491-2009, 2009.

Ng, N. L., Kroll, J. H., Chan, A. W. H., Chhabra, P. S., Flagan, R. C., and Seinfeld, J. H.: Secondary organic aerosol formation from m-xylene, toluene, and benzene, Atmos. Chem. Phys., 7, 3909-3922, doi:10.5194/acp-7-3909-2007, 2007.

Pankow, J. F.: Gas/particle partitioning of neutral and ionizing compounds to single and multi-phase aerosol particles. 1. Unified modeling framework, Atmos. Environ., 37, 3323-3333, 2003.

Pankow, J. F. and Barsanti, K. C.: The carbon number-polarity grid: a means to manage the complexity of the mix of organic compounds when modeling atmospheric organic particulate matter, Atmos. Environ., 43, 2829-2835, 2009.

Pankow, J. F., Niakan, N., and Asher, W. E.: Combinatorial variation of structure in considerations of compound lumping in one- and two-dimensional property representations of condensable atmospheric organic compounds. 1. Lumping by $1-\mathrm{D}$ volatility with $\mathrm{n}_{\mathrm{C}}$ fixed, Atmos. Environ., 80, 172-183, 2013.

Perraud, V., Bruns, E. A., Ezell, M. J., Johnson, S. N., Yu, Y., Alexander, M. L., Zelenyuk, A., Imre, D., Chang, W. L., Dabdub, D., Pankow, J. F., and Finlayson-Pitts, B. J.: Nonequilibrium atmospheric secondary organic aerosol formation and growth, $\mathrm{P}$. Natl. Acad. Sci. USA, 109, 2836-2841, 2012.

Rossignol, S., Chiappini, L., Perraudin, E., Rio, C., Fable, S., Valorso, R., and Doussin, J. F.: Development of a parallel sampling and analysis method for the elucidation of gas/particle partitioning of oxygenated semi-volatile organics: a limonene ozonolysis study, Atmos. Meas. Tech., 5, 1459-1489, doi:10.5194/amt-51459-2012, 2012.

Saleh, R., Donahue, N. M., and Robinson, A. L.: Time scales for gas-particle partitioning equilibration of secondary organic aerosol formed from alpha-pinene ozonolysis, Environ. Sci. Technol., 47, 5588-5594, 2013.

Shilling, J. E., Chen, Q., King, S. M., Rosenoern, T., Kroll, J. H., Worsnop, D. R., DeCarlo, P. F., Aiken, A. C., Sueper, D., Jimenez, J. L., and Martin, S. T.: Loading-dependent elemental composition of $\alpha$-pinene SOA particles, Atmos. Chem. Phys., 9, 771-782, doi:10.5194/acp-9-771-2009, 2009. 
Shiraiwa, M., Zuend, A., Bertram, A. K., and Seinfeld, J. H.: Gasparticle partitioning of atmospheric aerosols: interplay of physical state, non-ideal mixing and morphology, Phys. Chem. Chem. Phys., 15, 11441-11453, 2013.

Song, M., Marcolli, C., Krieger, U. K., Zuend, A., and Peter, T.: Liquid-liquid phase separation and morphology of internally mixed dicarboxylic acids/ammonium sulfate/water particles, Atmos. Chem. Phys., 12, 2691-2712, doi:10.5194/acp-12-26912012, 2012.

Stenzel, A., Goss, K.-U., and Endo, S.: Prediction of partition coefficients for complex environmental contaminants: Validation of COSMOtherm, ABSOLV, and SPARC, Environ. Toxicol. Chem., 33, 1537-1543, 2014.

Valorso, R., Aumont, B., Camredon, M., Raventos-Duran, T., Mouchel-Vallon, C., Ng, N. L., Seinfeld, J. H., Lee-Taylor, J., and Madronich, S.: Explicit modelling of SOA formation from $\alpha$-pinene photooxidation: sensitivity to vapour pressure estimation, Atmos. Chem. Phys., 11, 6895-6910, doi:10.5194/acp-116895-2011, 2011.

Virtanen, A., Joutsensaari, J., Koop, T., Kannosto, J., Yli-Pirila, P., Leskinen, J., Makela, J. M., Holopainen, J. K., Pöschl, U., Kulmala, M., Worsnop, D. R., and Laaksonen, A.: An amorphous solid state of biogenic secondary organic aerosol particles, Nature, 467, 824-827, 2010.

Volkamer, R., Ziemann, P. J., and Molina, M. J.: Secondary Organic Aerosol Formation from Acetylene $\left(\mathrm{C}_{2} \mathrm{H}_{2}\right)$ : seed effect on SOA yields due to organic photochemistry in the aerosol aqueous phase, Atmos. Chem. Phys., 9, 1907-1928, doi:10.5194/acp9-1907-2009, 2009.

Wang, C., Lei, Y. D., Endo, S., and Wania, F.: Measuring and modeling the salting out effect in ammonium sulfate solutions, Environ. Sci. Technol., 48, 13238-13245, 2014.
Wania, F., Lei, Y. D., Wang, C., Abbatt, J. P. D., and Goss, K.-U.: Novel methods for predicting gas-particle partitioning during the formation of secondary organic aerosol, Atmos. Chem. Phys., 14, 13189-13204, doi:10.5194/acp-14-13189-2014, 2014.

Westgate, J. N. and Wania F.: Model-based exploration of the drivers of mountain cold-trapping in soils, Environ. Sci.: Processes Impacts, 15, 2220-2232, 2013.

Wexler, A. S. and Clegg, S. L.: Atmospheric aerosol models for systems including the ions $\mathrm{H}^{+}, \mathrm{NH}_{4}^{+}, \mathrm{Na}^{+}, \mathrm{SO}_{4}^{2-}$, $\mathrm{NO}_{3}^{-}, \mathrm{Cl}^{-}, \mathrm{Br}^{-}$and $\mathrm{H}_{2} \mathrm{O}$, J. Geophys. Res., 107, 4207, doi:10.1029/2001JD000451, 2002.

Wong, F. and Wania, F.: Visualising the equilibrium distribution and mobility of organic contaminants in soil using the chemical partitioning space, J. Environ. Monit., 13, 1569-1578, 2011.

Wyche, K. P., Monks, P. S., Ellis, A. M., Cordell, R. L., Parker, A. E., Whyte, C., Metzger, A., Dommen, J., Duplissy, J., Prevot, A. S. H., Baltensperger, U., Rickard, A. R., and Wulfert, F.: Gas phase precursors to anthropogenic secondary organic aerosol: detailed observations of 1,3,5-trimethylbenzene photooxidation, Atmos. Chem. Phys., 9, 635-665, doi:10.5194/acp-9-635-2009, 2009.

You, Y., Renbaum-Wolff, L., Carreras-Sospedra, M., Hanna, S. J., Hiranuma, N., Kamal, S., Smith, M. L., Zhang, X., Weber, R. J., Shilling, J. E., Dabdub, D., Martin, S. T., and Bertram, A.: $\mathrm{K}$. Images reveal that atmospheric particles can undergo liquidliquid phase separations, P. Natl. Acad. Sci. USA, 109, 13188 13193, 2012.

Zuend, A. and Seinfeld, J. H.: Modeling the gas-particle partitioning of secondary organic aerosol: the importance of liquidliquid phase separation, Atmos. Chem. Phys., 12, 3857-3882, doi:10.5194/acp-12-3857-2012, 2012. 